BANCA D'ITALIA

E U R O S I S T E M A

Questioni di Economia e Finanza

(Occasional Papers)

Methodological issues in the estimation of current account imbalances

by Valerio Della Corte and Claire Giordano 

13 BANCA D'ITALIA

E U R O S I S T E MA

\section{Questioni di Economia e Finanza}

(Occasional Papers)

Methodological issues in the estimation of current account imbalances

by Valerio Della Corte and Claire Giordano

Number 617 - April 2021 
The series Occasional Papers presents studies and documents on issues pertaining to the institutional tasks of the Bank of Italy and the Eurosystem. The Occasional Papers appear alongside the Working Papers series which are specifically aimed at providing original contributions to economic research.

The Occasional Papers include studies conducted within the Bank of Italy, sometimes in cooperation with the Eurosystem or other institutions. The views expressed in the studies are those of the authors and do not involve the responsibility of the institutions to which they belong.

The series is available online at www.bancaditalia.it.

ISSN $1972-6627$ (print)

ISSN 1972-6643 (online)

Printed by the Printing and Publishing Division of the Bank of Italy 


\title{
METHODOLOGICAL ISSUES IN THE ESTIMATION OF CURRENT ACCOUNT IMBALANCES
}

\author{
by Valerio Della Corte* and Claire Giordano *
}

\begin{abstract}
The study outlines the main challenges when setting up a "current account (CA) model" in order to measure external imbalances. This model is a reduced-form relationship between the CA balance and a set of CA fundamental and policy drivers, from which a CA "norm" may be derived and against which the actual CA balance is appraised. After having formally outlined a standard CA model similar to those developed by the main international institutions, the paper raises several concerns in CA modelling, amongst which the measurement and selection of both the dependent and explanatory variables and some technical issues in the estimation procedure. Recent trends affecting the CA balance, such as the expansion of global firms and the rise in corporate saving, as well as the outbreak of the COVID-19 pandemic, are also discussed. The paper does not prescribe fully-fledged solutions to the manifold issues discussed, but rather aims to raise awareness of the latter, as well to provide some hints on how to tackle at least some of these challenges.
\end{abstract}

JEL Classification: F00, F20, F32, F41.

Keywords: current account balance, cyclically-adjusted current account, external imbalances. DOI: $10.32057 / 0$. QEF.2021.617

\section{Contents}

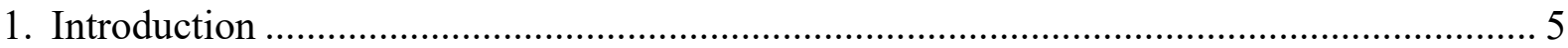

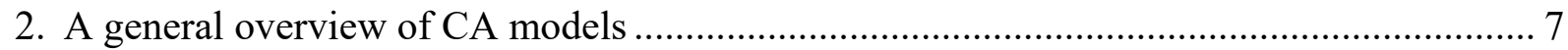

2.1 The CA balance from an accounting perspective ....................................................... 7

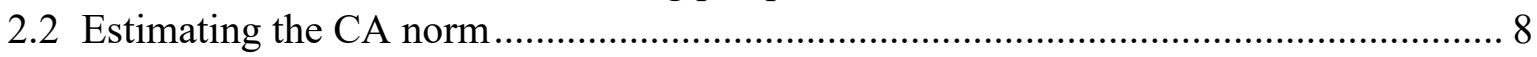

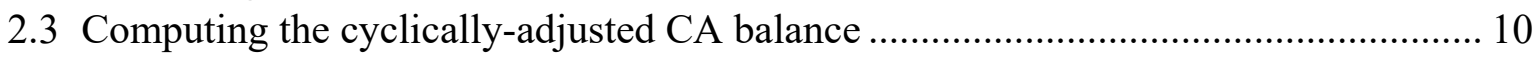

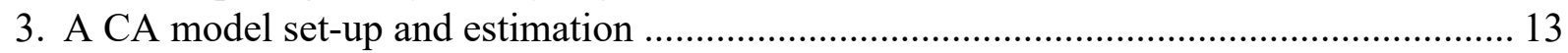

3.1 A review of the CA determinants suggested by the literature ................................... 13

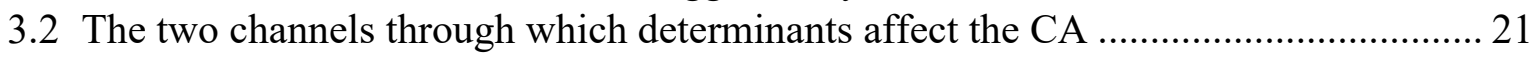

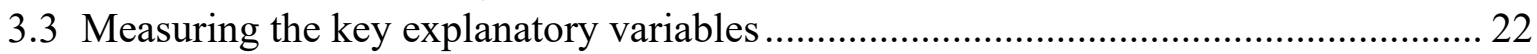

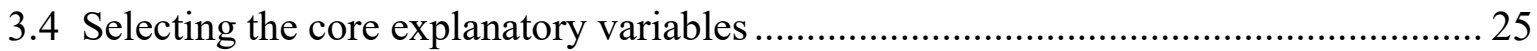

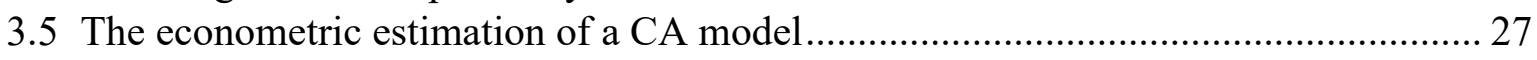

4. Recent and future challenges to CA modelling ............................................................... 28

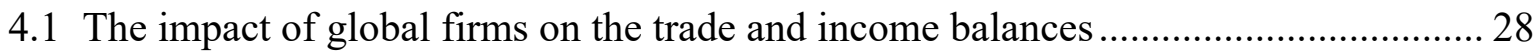

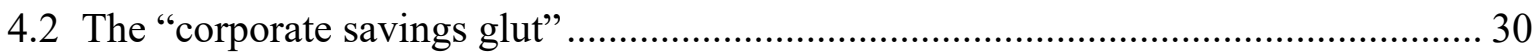

4.3 The current COVID-19 pandemic: a global shock to CA balances ........................... 31

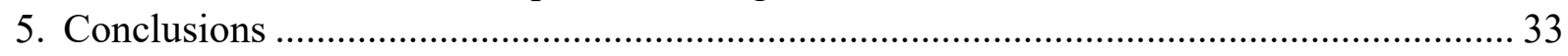

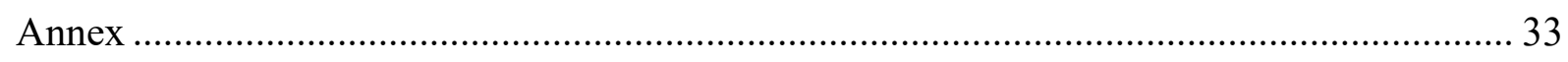

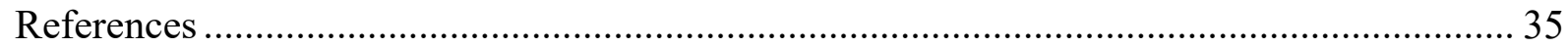

* Bank of Italy, Directorate General for Economics, Statistics and Research. 



\section{$1 \quad$ Introduction $^{1}$}

In the past decade of strong global financial and economic turmoil, the detection, the surveillance and the correction of external imbalances has become of paramount importance for policymakers. Amongst these, developments and potential disequilibria in the current account $(\mathrm{CA})$ - which largely reflect, on the one hand, changes in foreign trade in goods and services of a given country and, on the other hand, net saving decisions of resident economic agents - are an important signal.

CA deficits or surpluses can be economically optimal. Indeed, some countries may need to run CA deficits to finance growth-enhancing domestic investment opportunities, which generate future income to pay back foreign investors at a later stage, while other countries may accumulate external assets via CA surpluses in order to have sufficient financial resources to sustain future expenditure, for example due to unfavourable demographic trends. "Excessive" CA surpluses or deficits, i.e. external imbalances, may however lead to macroeconomic and financial vulnerabilities, which are to be avoided: for instance, a large reliance on foreign funding may expose a given country to sudden stops or to capital flows reversals and, hence, to a financial crisis.

Focusing on euro-area countries as an example, Spain's CA deficit amounted to 10 per cent of its GDP before the outbreak of the global financial crisis at the end of the 2000s, but it has turned into a surplus since then (Fig. 1). Conversely, by 2016 Germany's surplus had reached approximately 9 per cent of GDP and only modestly decreased thereafter. This evidence begs the question of whether a given country's CA balance is consistent with a CA benchmark or "norm", and is hence sustainable in the medium-term, or whether corrections are indeed warranted.

The measurement of potential CA imbalances is core to answer this question. For example, amongst its 14 headline indicators, the European Commission (EC)'s Macroeconomic Imbalance Procedure (MIP) Scoreboard includes the three-year backward moving average of the CA balance in percentage of GDP, with potential imbalance thresholds fixed at +6 and -4 per cent. ${ }^{2}$ In addition, several international institutions, such as the International Monetary Fund (IMF) and, again, the EC, have developed fully-fledged CA models (Cubeddu et al., 2019 and Coutinho et al., 2018, respectively), which define or estimate the CA norm for a given country against which its actual CA balance is appraised in order to gauge potential imbalances. ${ }^{3}$

This endeavour, however, represents a challenge given the high number of factors that may affect the determination of CA balances and the complexity of the mechanisms at play. Accordingly, the literature on the topic is vast and little consensus prevails on what is the best

\footnotetext{
${ }^{1}$ The authors thank Silvia Fabiani, Stefano Federico, Alberto Felettigh and Alfonso Rosolia for comments on previous versions of this paper. The views expressed in the article are those of the authors and do not necessarily reflect those of the Bank of Italy

${ }^{2}$ European Commission (2012) explains the choice of these asymmetric thresholds, in turn based on long-run empirical studies, by claiming that large CA surpluses do not raise the same concerns as CA deficits about the sustainability of external debt and financing capacities, which can affect the smooth functioning of the euro area, a key criterion for triggering the corrective arm of the MIP and for urgent policy intervention.

${ }^{3}$ The Bank of Italy has not developed a comprehensive CA model, yet it provides estimates of the so-called cyclically-adjusted CA balance, which will be later explained. Moreover, real effective exchange rate (REER) misalignments, the other significant form of external imbalances, are periodically estimated, according to a quarterly Behavioural Equilibrium Exchange Rate (BEER) model, first put forward in Fidora et al. (2021) and further developed in Giordano (2020).
} 
Figure 1: Current account balances of the main euro-area countries

(percentages of GDP; four-quarter moving averages)

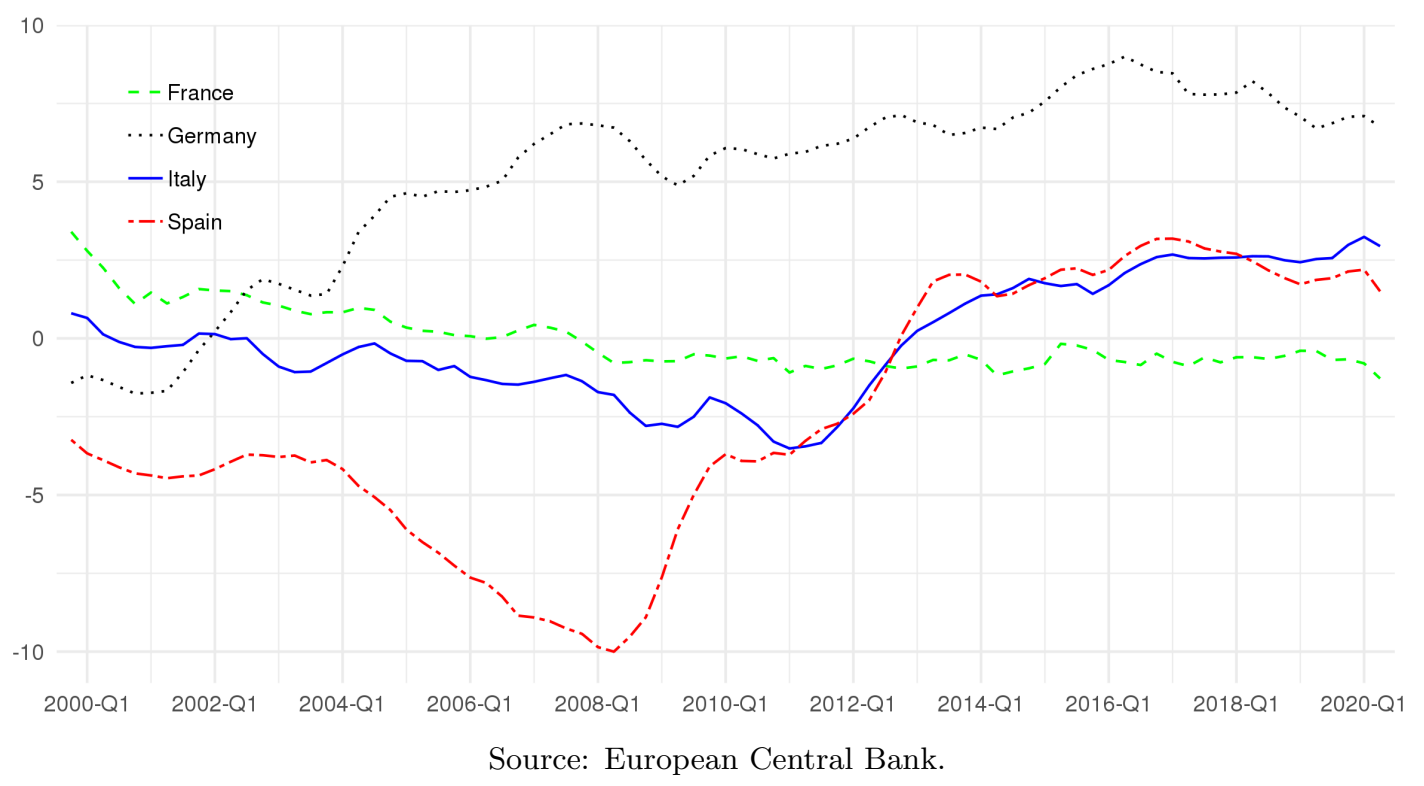

approach, each having specific advantages and drawbacks, and at times yielding very different results.

This paper discusses the various modelling and measurement issues a researcher faces when setting up and estimating a CA model, hence providing a comprehensive critical review. In this respect, it adds to the existing methodological literature that assesses the manifold issues underlying the measurement of various types of external imbalances (e.g. Bussière et al., 2010; Adler and Grisse, 2017; Giordano, 2021).

In particular, after having defined the CA balance, sketched a general CA model and discussed the computation of cyclically-adjusted CA balances, we structure our discussion around five main topics. The first refers to the possible determinants of the CA, i.e. the explanatory variables to be included in the $\mathrm{CA}$ model, based on the existing theoretical and empirical literature. The second theme concerns the choice of the target or dependent variable: the CA balance or its two accounting components, the national savings and investment rates. The third issue is how to accurately measure several key variables of a CA model. The fourth is how to select the significant explanatory variables of a $\mathrm{CA}$ model, given the large range of potential drivers suggested by the literature. The last topic concerns the choice of the most appropriate estimation methodology of the CA model, once specified.

During recent years CA balances have been influenced by shifts in the global economy, due for example to the rise in weight of multinational enterprises (MNEs), the resulting growing contribution of the (investment) income balance to the CA balance and the increasing role of corporate savings in determining CA surpluses. Furthermore, at the time of writing of this paper the global economy was hit by the COVID-19 pandemic, an additional, unexpected game-changer. A final section is hence devoted to some (at this stage highly speculative) 
considerations on these most recent challenges and how the health emergency in particular may affect CA modelling in the future.

The remainder of this paper is organised as follows. Section 2 defines the CA balance, describes the general structure of a CA model and refers to alternative ways of modelling the cyclically-adjusted CA balance. Section 3 discusses the afore-mentioned five general issues concerning the set-up and the estimation of the model. Section 4 speculatively discusses the possible impact of recent trends in globalization and of the COVID-19 pandemic on CA modelling. Section 5 draws some conclusions.

\section{A general overview of CA models}

\subsection{The CA balance from an accounting perspective}

According to the IMF's Balance of Payments Manual 6 (BPM6) definition, the CA balance records the difference between the sum of exports and income receipts on domestically-owned factors of production (capital and labour) that are employed abroad and the sum of imports and income payments to foreign-owned factors of production employed at home. In formal terms:

$$
C A=\underbrace{X-M}_{\text {Trade balance }}+B P I+B S I
$$

Exports $(\mathrm{X})$ and imports $(\mathrm{M})$ refer to trade in both goods and services and their balance is commonly known as the trade balance. Income refers to both primary (BPI) and secondary income (BSI). The primary income balance accounts for income inflows and outflows of an economy's residents vis-à-vis non-residents, decomposed into labour income (i.e. compensation of employees), investment income, in turn related to the income generated on international financial assets and liabilities, and other income (rents on natural resources aboard, taxes and subsidies on products and production, etc.). The secondary income balance captures international unreciprocated payments and receipts, for example transfers between governments and international organisations, such as emergency aid, technical assistance and migrants' remittances.

The CA balance is equal to the difference between national saving and investment on the basis of national accounts (NA) identities. Gross national disposable income (GNDY) is the total income earned by the residents of an economy, including that which is generated abroad and is given by the sum of the gross domestic product (GDP) and net income from abroad:

$$
G N D Y=G D P+B P I+B S I
$$

where GDP can be rewritten according to the expenditure approach, leading to the following equation:

$$
G N D Y=\underbrace{C+G+I+X-M}_{G D P}+B P I+B S I
$$

where $\mathrm{C}$ is household consumption, $\mathrm{G}$ is government consumption and $\mathrm{I}$ is gross fixed capital formation. By reshuffling its components, Equation 3 can be rewritten as:

$$
\underbrace{G N D Y-C-G}_{S:=\text { gross savings }}-I=\underbrace{X-M+B P I+B S I}_{C A:=\text { Current account balance }}
$$


The CA balance can be hence represented as the excess of saving over investment:

$$
C A=S-I .
$$

Clearly and as mentioned in the introduction, a CA deficit (surplus) does not per se necessarily imply an imbalance, as it can make sense, for example, for an emerging (advanced) economy to borrow (to lend) vis-à-vis the rest of the world against future income.

\subsection{Estimating the CA norm}

Two main alternative approaches are currently used in surveillance to measure CA imbalances, often employed as cross-consistency checks, for example in the case of the IMF's annual External Balance Assessment (EBA).

The first approach ("External Sustainability Approach"), put forward in Isard and Faruqee (1998), consists in estimating the CA balance that allows reaching or maintaining a target level for the Net International Investment Position (NIIP). As discussed in Coutinho et al. (2018), the resulting CA benchmarks are commonly interpreted as prudential thresholds for external sustainability, that is as a lower limit that the CA needs to reach to stabilise an NIIP position that would otherwise be deteriorating or an upper limit if the NIIP is growing. A key assumption concerns the level at which the NIIP is to be stabilised, often viewed as its current level, a minimum requirement in case of large CA deficits and large stocks of net foreign liabilities, such that the country's NIIP does not deteriorate any further. ${ }^{4}$ Moreover, these CA benchmarks rely on partial equilibrium equations representing NIIP dynamics, in which all other variables are assumed to be exogenous.

The second approach, inaugurated by Faruqee and Debelle (1996), is based on the estimation of country-specific and time-varying CA norms. It implies the estimation of a reduced-form equation, which leads to the computation of a CA norm that is consistent with economic fundamentals, against which actual CA balances are appraised. This methodology aims at detecting past systematic empirical regularities between the CA and its medium-term determinants, and is hence not able nor set up to tackle causality, which only a structural approach would allow. ${ }^{5}$ In this paper we will focus on these reduced-form models, loosely defined hereon as "CA models".

In formal terms, for each country $i$ at time $t$ a simple CA model estimates the reduced-form relationship between the CA balance (in percentage of GDP; $C A$ ) and a set of "fundamentals" $\left(X^{F}\right)$ and non-fundamental variables, in turn including both cyclical factors $\left(X^{C}\right)$ and policy variables $\left(X^{P}\right)$ :

$$
C A_{i, t}=\alpha+\beta^{\prime} X_{i, t}^{F}+\psi^{\prime} X_{i, t}^{C}+\gamma^{\prime} X_{i, t}^{P}+\epsilon_{i, t}
$$

where $\epsilon_{i, t}$ is the error term.

\footnotetext{
${ }^{4}$ Abstracting from errors and omissions and assuming valuation effects to net out to zero, the CA balance and the growth of nominal GDP are the main drivers of the evolution of the NIIP/GDP ratio. The CA stabilising the NIIP at its current level is hence a function of this current level, of nominal growth in GDP and of the capital account balance, where the latter is generally small. Also see Bussière et al. (2010) for a more sophisticated derivation of the NIIP-stabilising level, based on potential output growth and inflation rates.

${ }^{5}$ Similarly to BEER models for the estimation of real exchange rate imbalances (e.g. Giordano, 2021), in the econometric sense there is indeed no presumption that the right-hand-side variables are independent of the error term.
} 
Many studies, amongst which Chinn and Prasad (2003), Ca' Zorzi et al. (2012), MoralBenito and Roehn (2016) and Coulibaly et al. (2018), remove cyclical factors from the model by using non-overlapping averages of data over fixed (e.g. five or ten-year) time-spans. However, this procedure, as well as arbitrarily imposing a fixed duration of business cycles to all countries, significantly restricts the estimation sample, thereby reducing the information content of the data. More refined models (e.g. Cubeddu et al., 2019; Coutinho et al., 2018) are estimated on annual data and explicitly account for cyclical factors, as in Equation 6, which we hence consider as the workhorse model.

In order to ensure multilateral consistency, since CA balances depend not only on domestic but also on foreign developments, and whenever is meaningful, explanatory variables are constructed relative to world averages (for example, GDP-weighted, as in Chinn and Ito, 2007 and Cubeddu et al., 2019, or trade-weighted, as in Bussière et al., 2010, Ca' Zorzi et al., 2012 and Moral-Benito and Roehn, 2016). This transformation also applies to policy variables, allowing for a decomposition of their effect on a given country's CA into its domestic and foreign components.

Let $X^{P^{*}}$ denote values of policy variables that are deemed desirable, which may or may not coincide with actual values $X^{P}$. Then, the predicted CA can be decomposed into three components: the (cyclically-adjusted) CA norm, the cyclical component and the policy gap:

$$
C \hat{A}_{i, t}=\underbrace{\hat{\alpha}+\hat{\beta}^{\prime} X_{i, t}^{F}+\hat{\gamma} X^{P^{*}}}_{\text {CA norm }}+\underbrace{\hat{\psi}^{\prime} X_{i, t}^{C}}_{\text {Cyclical component }}+\underbrace{\hat{\gamma}\left(X^{P}-X^{P^{*}}\right)}_{\text {Policy gap }}
$$

As seen in Equation 7, the CA norm $\left(C A_{i, t}^{\text {Norm }}\right)$ is computed on the basis of the contributions solely of economic fundamentals and of desirable policy levels. In order to define the desirable policy levels for a given country, a normative assessment is necessary (Cubeddu et al., 2019). Note that if policy variables are specified as deviations from world averages, policy gaps appear only if a country's policy distortion is different from their corresponding world average.

An alternative approach, adopted by the EC, is to interpret world averages for policy variables as desirable levels and to assume that country-specific policy variables are in line with world averages: hence, the policy gap for all countries is zero. As a result, $X^{P}$ drops out from Equation 6 and the norm in this case is defined more simply as follows:

$$
C A_{i, t}^{N o r m}=\hat{\alpha}^{F}+\hat{\beta}^{\prime} X_{i, t}^{F}
$$

where $\hat{\alpha}^{F}$ is given by $\overline{C A}-\hat{\beta}^{\prime} \overline{X^{F}}$ and the bars denote averages.

However defined, the CA norm is then used as a benchmark value not for the headline CA balance but for the CA balance adjusted for business-cycle effects, the so-called cyclicallyadjusted CA balance, generally defined as follows:

$$
\mathrm{CACA}_{i, t}=C A_{i, t}+\underbrace{\eta_{i, t}}_{\text {Cyclical adjustment }}
$$

Finally, a "CA imbalance" is then derived as the percentage-point difference between the cyclically-adjusted CA and the CA norm:

$$
\mathrm{CAimb}_{i, t}=\mathrm{CACA}_{i, t}-C A_{i, t}^{\text {Norm }}
$$




\subsection{Computing the cyclically-adjusted CA balance}

In general, as defined in Equation 9, the cyclically-adjusted CA balance is obtained as the headline $\mathrm{CA}$ balance with a correction due to the cyclical component. In all existing methodologies to our knowledge, the effect of the business cycle on the CA is assumed to be reflected solely in the trade balance, while it could be the case that the primary and secondary income balances also vary with output fluctuations. However, the relation between CA components other than the trade balance and the business cycle does not lend itself to an intuitive modelling and therefore this channel is generally neglected.

The IMF follows a straightforward approach to cyclical adjustment as it simply subtracts from the headline CA balance the predicted value obtained using the cyclical variables drawn from Equation 7, such that the cyclical adjustment term is defined as follows:

$$
\eta_{i, t}=-\hat{\psi}^{\prime} X_{i, t}^{C}
$$

In particular, the cyclical variables considered in Cubeddu et al. (2019) are the country's relative output gap (with respect to the GDP-weighted world output gap average) and its commodity terms-of-trade gap (relative to the country-specific trend), interacted with the country's degree of trade openness. The first variable aims at capturing the impact on the CA balance of the relative position in the business cycle of a country relative to its main trading partners, in particular via the trade balance: a booming domestic economy usually results in high imports, lowering the CA balance on a temporary basis, while a favourable global cycle implies that foreign demand will likely stimulate exports, boosting the CA balance in the short run. The second variable measures the effect of deviations of a country's commodity terms-of-trade index from its country-specific trend, given that improvements in terms of trade usually determine a higher trade balance, and is interacted with trade openness, since a larger impact on the CA balance is expected for more open economies. ${ }^{6}$

The EC instead interprets the cyclically-adjusted CA balance of a given country as the CA balance that would prevail if the output gaps of the country and of its trade partners were zero, i.e. if both domestic and foreign demand ${ }^{7}$ were at their potential (Coutinho et al., 2018) and exports and imports responded proportionately. This leads to measuring the cyclical adjustment term in the following manner:

$$
\eta_{i, t}=\frac{1}{Y_{t}}[\theta_{M} M_{t} \underbrace{\frac{Y_{t}-Y_{t}^{*}}{Y_{t}^{*}}}_{\text {Domestic output gap }}-\theta_{X} X_{t} \underbrace{\frac{Y_{t}^{F}-Y_{t}^{* F}}{Y_{t}^{* F}}}_{\text {Foreign output gap }}]
$$

where $Y_{t}\left(Y_{t}^{F}\right)$ defines actual nominal domestic (foreign) GDP at time $t$, the asterisks denote nominal potential levels, $M_{t}\left(X_{t}\right)$ captures the country's imports (exports), $\theta_{M}\left(\theta_{X}\right)$ the corresponding trade elasticity to GDP. In this formulation it is assumed that the activation of

\footnotetext{
${ }^{6}$ The IMF estimates that an increase in the relative output gap of 1 per cent reduces the CA balance by about 0.35 percentage points of GDP and that a 10 per cent temporary gain in terms of trade is associated with a 0.8 percentage point increase in the CA balance for a country with an openness degree of 50 per cent of GDP.

${ }^{7}$ Defined as a weighted average of imports of trading partners, with weights given by their share in the home country's nominal goods exports.
} 
imports (exports) associated with domestic (foreign) output is constant and independent of output movements; therefore, the amount of imports (export) that stems from closing the current home (foreign) output gap is simply given by the product of elasticity of imports (exports), of current imports (exports) and of the current (foreign) output gap. Moreover, both import and export elasticities to GDP are set by the EC to 1.5 for all countries, although the empirical literature points to a relatively large dispersion in these elasticities across countries and periods. By assuming a fixed import elasticity in particular, the EC methodology neglects composition effects in aggregate demand, i.e. the fact that the latter's different components activate imports with different intensities (e.g. Bussière et al., 2013). It also does not take into account the fact that the evolution of exports, driven by the foreign output gap, feeds back into the domestic output gap and that treating these variables as independent is not entirely correct.

The Bank of Italy (Fabiani et al., 2016) overcomes this last issue by developing a model that posits that real imports are isoelastic (i.e. present a constant elasticity relative) to a reducedform import-intensity-adjusted demand (IAD) variable, in turn a convex combination of both exports and domestic demand.

In formal terms, let $\Delta M_{t}^{*}\left(\Delta X_{t}^{*}\right)$ be the difference between "potential" imports (exports) and current imports (exports) at time $t$. Since exports are assumed to be isoelastic to overall foreign demand as in Coutinho et al. (2018), ${ }^{8} \Delta X_{t}^{*}$ is equivalent to the second term inside the square brackets of Equation 12:

$$
\Delta X_{t}^{*}=-\theta_{X} X_{t} \frac{Y_{t}^{F}-Y_{t}^{* F}}{Y_{t}^{* F}}
$$

The key difference with the EC methodology lies instead on the import side:

$$
\Delta M_{t}^{*}=M_{t} \theta_{M}^{I A D} \omega_{x} \frac{M_{t}}{X_{t}} \Delta X^{*}+\theta_{M}^{I A D}\left(1-\omega_{x}\right) \frac{M_{t}}{D D_{t}} \Delta D D_{t}^{*}
$$

where $\theta_{M}^{I A D}$ is the constant long-run elasticity of imports to IAD, in turn a geometric weighted average of the demand components, with weights reflecting their relative imports contents; $\omega_{x}$ is the weight of exports in constructing the IAD variable and $\left(1-\omega_{x}\right)$ is the weight of domestic demand $D D_{t} ; \Delta D D_{t}^{*}$ is the difference between the potential domestic demand and the current domestic demand.

The model can be solved by imposing the NA identity for GDP (applied to the potential level of all variables):

$$
Y_{t}^{*}=D D_{t}^{*}+X_{t}^{*}-M_{t}^{*}
$$

and substituting out $M^{*}$ using Equation 14, then solving for $Y_{t}^{*}, X_{t}^{*}$ and finally $D D_{t}^{*}$. This provides an equation for $\Delta M^{*}$ expressed in terms solely of given parameters, which can thus be brought to the data (actual trade flows from NA and exogenous potential domestic, foreign output gap and potential exports as obtained by Equation 13). It also solves the inconsistency issue underlying the EC methodology.

The cyclical adjustment term is then given by:

$$
\eta_{i, t}=\frac{1}{Y_{t}}\left[\Delta M_{t}^{*}-\Delta X_{t}^{*}\right]
$$

\footnotetext{
${ }^{8}$ Disentangling the various components of the rest of the world's countries' domestic demand and their different activation intensity is indeed extremely cumbersome data-wise.
} 
Figure 2: The cyclically-adjusted current account balance of Italy according to different methodologies

(percentages of GDP)

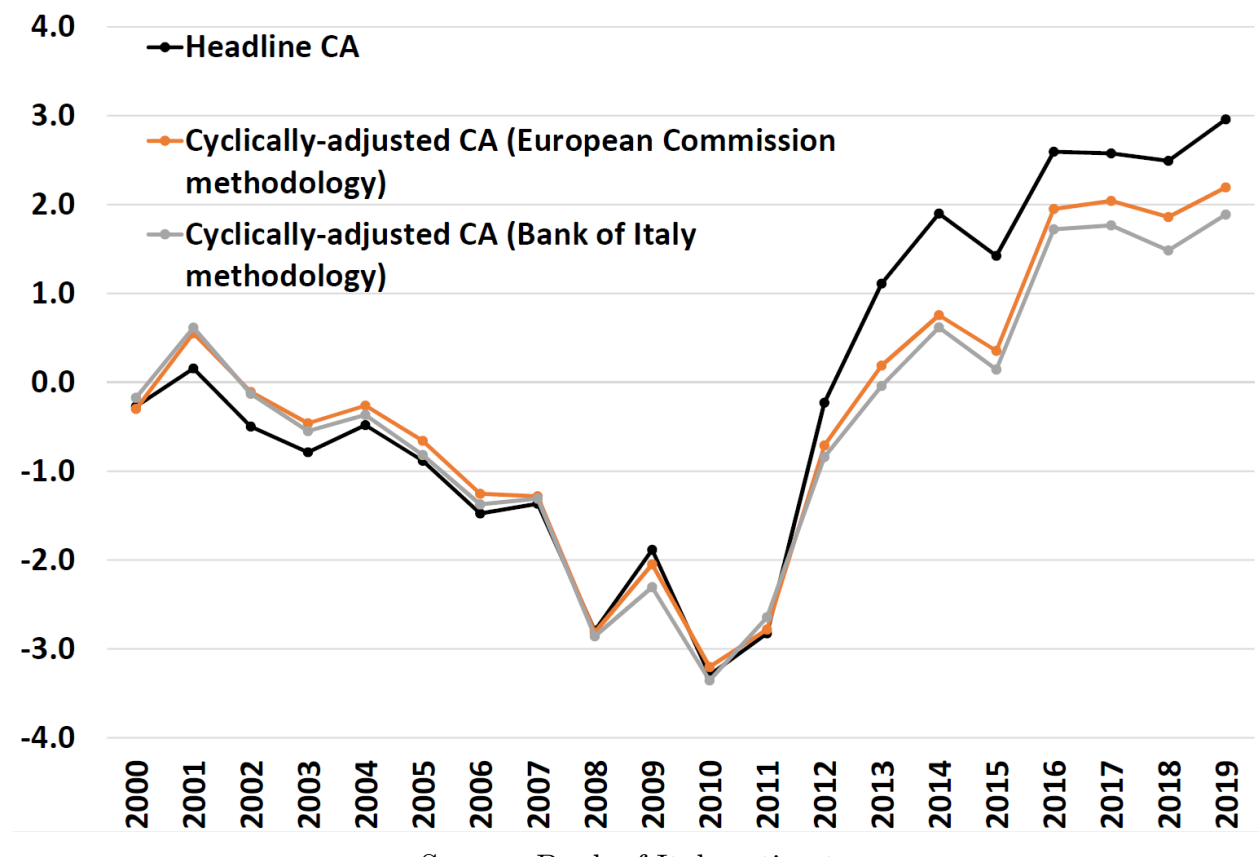

Source: Bank of Italy estimates.

This more refined computation of potential imports has a non-negligible impact on the cyclically-adjusted CA balance, also due to the different calibration of the trade elasticities. ${ }^{9}$ The impact is exemplified in Figure 2 referred to Italy, which compares estimates based on the EC and the Bank of Italy's models, respectively. Since 2012 the Bank of Italy's cyclical adjustment has indeed been slightly larger than the EC's correction, implying a lower cyclicallyadjusted CA balance.

However measured (IMF, EC or Bank of Italy methods), the cyclical adjustment term of the CA is highly sensitive to the set of output gap estimates employed in the computations. It is known that the latter figures vary significantly across institutions, given the high uncertainty surrounding these measures, and the resulting cyclical adjustment terms of the CA can therefore turn out to be different. As an example, in the twenty years from 2000 to 2019 the domestic output gap estimated by the EC was on average half a percentage point (in GDP terms) lower than that estimated by the Bank of Italy (which are those used by Fabiani et al., 2016) ${ }^{10}$ If the EC had assumed the same domestic output gap as that of the Bank of Italy, the cyclical adjustment would have been 0.1 percentage points of GDP larger, ceteris paribus (i.e. keeping the methodology fixed as in Equation 12).

After having outlined the possible ways to measure the cyclically-adjusted CA balance, we

\footnotetext{
${ }^{9}$ Based on the empirical findings in Bussière et al. (2013), for example Fabiani et al. (2016) assumes $\theta_{X}=1.896$ and $\theta_{M}^{I A D}=1.592$. for Italy.

${ }^{10}$ In turn, the methodology underlying the output gaps estimated at the Bank of Italy is discussed in Bassanetti et al. (2010).
} 
now turn to five general modelling choices to be undertaken when setting up a CA model.

\section{A CA model set-up and estimation}

\subsection{A review of the CA determinants suggested by the literature}

An early framework for examining CA developments is the "elasticities approach", put forward in Goldstein and Khan (1985). Exports (imports) are modeled as a function of relative prices between the exporting (importing) country and the rest of the world (i.e. the real effective exchange rate, REER), as well as of foreign (domestic) income or demand. The trade balance is thus expected to respond positively to foreign demand and negatively to the REER. As discussed in Isard and Faruqee (1998) and Gagnon (2017), the REER is considered as playing a key role as an equilibrating mechanism in the CA adjustment process, but only in the short run. This trade elasticity approach hence is inherently limited in its ability to explain "equilibrium" CA positions, since it mainly focuses on the proximate, as opposed to medium-to-long-run, drivers of CA balances. ${ }^{11}$

As illustrated in Section 2.1, the CA is also the outcome of national saving less domestic investment. This alternative viewpoint, which led to the so-called "absorption approach", stresses how macroeconomic factors ultimately determine international borrowing or lending patterns (Alexander, 1952). The more modern "inter-temporal representative approach" (Sachs, 1981; Obstfeld and Rogoff, 1995) extends the absorption approach through its recognition that the saving and investment decisions of representative agents - namely households, firms and governments - are the result of forward-looking optimization calculations based on expectations of future variables.

A third, alternative approach is to consider the aggregate trade balance, the key component of the CA balance, as the sum of all bilateral trade relations. This approach (e.g. Davis and Weinstein, 2002) implies investigating the possible determinants of bilateral trade balances, such as the role of highly specialized intermediate goods and of pairwise trade costs, in turn reflecting, for example, bilateral protectionist measures. However, the current dominant consensus among economists is that aggregate trade balances are linked to the evolution of macroeconomic factors that are relatively independent from a single trade relation (Feenstra et al., 1998; Felbermayr and Yotov, 2019; Eugster et al., 2020), so that bilateral balances are not actually relevant to the conduct of macroeconomic policy.

The most recent CA models are hence commonly grounded on the "inter-temporal representative approach". However, the precise empirical implications of this framework are not straightforward and there is no consensus about the correct model specification (Barnes et al., 2010). Indeed, under this general framework, specific theoretical models have different predictions about the macroeconomic drivers of the CA balance, as well as of their expected signs and magnitudes.

As mentioned in Section 2.2, one way of classifying the possible CA determinants is to group them into fundamental, cyclical and policy variables, although in practice the distinction across the three categories may not be clear-cut. We here attempt to adopt this classification in order to review the main drivers of the CA balance pinpointed by the existing literature.

\footnotetext{
${ }^{11}$ Moreover, the REER responds endogenously to all the driving factors behind the CA and is hence generally not included in CA models (e.g. Bussière et al., 2010; Gagnon, 2011). One rare exception is Unger (2017).
} 


\subsubsection{Fundamentals}

Income per capita. According to the standard neoclassical theory, relative income per capita is generally included in a CA model with the idea that capital shifts between countries at different stages of economic development, in particular from rich to poor economies, thus fostering so-called "downhill" capital flows (e.g. Isard and Faruqee, 1998; Chinn and Prasad, 2003; Gruber and Kamin, 2007). Under the standard assumptions of countries producing the same goods with the same constant returns to scale production technology using capital and labor as factors of production, differences in income per capita reflect differences in capital per capita. Hence, an economy that has low income and a low capital-labour ratio, provided it has access to international capital markets, will initially import capital from advanced economies and run CA deficits in order to build its capital stock while maintaining its long-run rate of consumption. Its relatively high marginal product of capital will indeed attract capital inflows from more advanced, relatively labor-scarce countries, and raise its external indebtedness up to the point in which the returns to investment are equalized across countries. ${ }^{12}$

Income squared. The square of relative income per capita is sometimes employed in CA regressions (e.g. Isard and Faruqee, 1998; Chinn and Prasad, 2003; Ca' Zorzi et al., 2012; Cheung et al., 2013) in order to capture the possibility that the marginal impact on CA balances increases for larger relative income gaps. This non-linearity is indeed consistent with lowincome countries having more difficulty in accessing international capital markets, in contrast, for instance, to countries in the middle stage of development.

Demography. Demographic factors affect the CA by mainly influencing the saving behaviour of the economy due to heterogeneity across different age groups. The life-cycle overlappinggenerations extension of the basic inter-temporal approach, for instance, suggests that the saving behaviour of households is hump-shaped (Higgins, 1998): savings are accumulated during the working age, while younger and older cohorts generally dissave. Thus, a country with a higher share of economically inactive population should generally be expected to save relatively less and hence lead to a lower CA balance. Moreover, countries save more when prime-aged savers expect to live longer, and more so when they cannot rely on future generations for old-age support. ${ }^{13}$ Finally, demographic heterogeneity across economies can reinforce the afore-mentioned "downhill" capital flows towards countries that are younger and are aging more slowly, namely emerging economies, leading to even higher CA balances in the exporter countries (e.g. Coeurdacier et al., 2018).

International migration. Linked to general demographic trends, Coulibaly et al. (2018) points to the possible role of migration in determining the CA balance. This variable indeed contributes to changing the demographic structure in both origin and destination countries. In general, high-income countries are characterized by increasing immigration, while low-income countries are marked by emigration. International migration mainly consists of working-age people, who tend to save, thereby improving the CA balance in the destination country and exerting the opposite effect in the origin country. ${ }^{14}$

\footnotetext{
${ }^{12}$ Obstfeld (1995) argues that the most direct approach to model this mechanism would be to compare the rate of return of capital across countries. However, it is difficult to find internationally comparable measures of after-tax returns to capital. Relative income per capita is hence the most common proxy.

${ }^{13}$ To the extent that capital-labour ratios are also affected via the number of available workers, changes in demographics may affect investment as well, although this channel is generally found to be weaker.

${ }^{14}$ Linked to the topic of migration, for certain emerging economies, workers' remittances provide a significant
} 
Oil status. Higher oil prices improve the CA balance of oil exporters, while they reduce that of oil importers. In order to capture this mechanism, the oil trade balance is often included in CA models (e.g. Rahman, 2008, Bussière et al., 2010 and Medina et al., 2010) ${ }^{15}$ or, as alternatives, oil consumption per capita, oil production value (e.g. Cheung et al., 2013) or a dummy for oil-exporting countries (e.g. Chinn and Prasad, 2003).

Foreign direct investment (FDI). Increased inward FDI often signals an improvement in the investment climate of a country, as well as providing for a more stable source of financing CA deficits (e.g. Rahman, 2008). A rise in FDI may foster investment in the home country. Higher FDIs tend to affect the CA balance also through increased imports, for example via enhanced infra-group trade. For these reasons, a negative relationship between FDI inflows and CA balance is expected. The coefficient is likely to depend on the import content of FDI and whether FDI increases investment or acquires existing capital stock. For similar reasons, Comunale (2016) includes in a CA model, in addition to net FDI flows, net portfolio investment and net other investment flows.

Real interest rate. Higher long-term real interest rates make current consumption more expensive compared with future consumption and therefore increases savings. They also increase the opportunity cost of investment. For both reasons they are expected to lead to an improvement in the CA balance (e.g. Barnes et al., 2010).

Reserve currency status. Issuers of reserve currencies, such as the United States, tend to benefit from lower funding costs due to high global demand for their assets, which are deemed as safe, leading to the so-called "exorbitant privilege". This status tends to tilt consumption towards the present and leads to higher investment in the reserve issuing economy (Cubeddu et al., 2019). Moreover, global demand for reserve assets tends to appreciate the currency of the reserve issuer, whose CA balance hence weakens.

Financial centre status. Some CA models include financial centre dummies in order to control for the impact on CA balances from a country being a centre for international financial flows (e.g. Rahman, 2008; Lane and Milesi-Ferretti, 2012). Indeed, financial centres tend to record large CA surpluses, such as Luxembourg or the Netherlands in Europe. Recent research has shown the positive relationship between the status of financial centres and the CA has become stronger in recent years (Di Nino et al., 2020). While quite common in the literature, a dummy approach may, however, be too restrictive, as will be discussed in more detail in Section 3.3 .

\subsubsection{Cyclical variables}

Output gap. As mentioned in Section 2.3, weak domestic demand, reflected in negative output gaps, leads to higher saving and lower investment, implying a dependence of CA balances on the (relative) state of the business cycle.

Terms of trade. Both changes in the levels and volatility of the terms of trade are expected to cyclically affect the CA (e.g. Isard and Faruqee, 1998; Cubeddu et al., 2019; Chinn and Prasad, 2003). In particular, changes in the terms of trade may capture the so-called "Harberger-

source of income, which can be saved or spent. To account for this, Rahman (2008), for example, includes in a CA model a dummy variable for countries where annual remittances are equal to or exceed 5 percent of GDP.

${ }^{15}$ Similarly to net foreign assets discussed later, this variable is not constructed relative to foreign trading partners, because this is implicit in its definition. 
Laursen-Metzler effect". Harberger (1950) and Laursen and Metzler (1950) postulated that a terms-of-trade deterioration decreases real income, which in turn reduces saving. Thus, if investment is constant and there is no government deficit, the change in saving is equal to the change in the CA balance, which hence will deteriorate. Svensson and Razin (1983), however, challenged this view by arguing that the changes in the trade, and hence, CA balance due to a terms-of-trade deterioration can be separated into three different effects: a direct effect, consisting of a revaluation of net exports; a wealth effect on consumption, since a terms-of-trade deterioration reduces wealth; and a substitution effect on consumption, due to relative price changes within and between periods. In general, the sum of these effects is of ambiguous sign, although the direct plus wealth effect is unambiguously negative (positive) for a temporary (future) terms-of-trade deterioration. In addition to changes in the terms of trade, agents in economies without full insurance that face more volatile terms of trade may find it desirable to save more for precautionary reasons in order to smooth their consumption in the face of volatile income flows, hence lowering the country's CA position. Economies with more volatile terms of trade may also be less attractive for international capital flows.

Commodity prices. Commodity prices or terms of trade are important cyclical factors (Cubeddu et al., 2019). ${ }^{16}$ The effect of oil price fluctuations on CA balances depends on whether a country is a net exporter or a net importer of oil, a structural factor that is often captured amongst the fundamental variables, as mentioned earlier. The size of the impact would then vary with how intensely a nation uses oil in its economy (for an importer) or with the relative importance of oil production in its economy (for an exporter).

Net foreign asset (NFA) position. Other cyclical variables are at times hard to disentangle from economic fundamentals. For example, some CA models, such as Coutinho et al. (2018), include the NIIP or the NFA position as a cyclical explanatory variable; other studies (e.g. Cubeddu et al., 2019; Coulibaly et al., 2018) treat this driver as a fundamental variable. ${ }^{17}$ Furthermore, the sign of its relationship with the CA is theoretically ambiguous. A large negative NFA position is associated with negative net investment income flows, which weaken the CA balance. On the other hand, inter-temporal considerations suggest an opposite effect: a highly indebted country may raise sustainability concerns and have to eventually improve its CA to preserve solvency.

GDP growth. Actual or expected real GDP growth is at times considered a cyclical variable (e.g. Bussière et al., 2010) and at times a fundamental (e.g. Cheung et al., 2013, Darvas, 2015; Coulibaly et al., 2018). The sign of its correlation with the CA balance depends on whether high growth rates are perceived as transitory or permanent: the CA improves in response to a transitory positive shock, but it worsens following a permanent positive shock, in that firms undertake higher investment, in anticipation of higher returns to capital, and households increase consumption and lower saving as a result of their expectation for higher future income. When considered as a fundamental variable, GDP growth is often employed to proxy changes in productivity growth (e.g. Gruber and Kamin, 2007), although it does not control for changes in labour-force participation nor in hours worked nor in capital intensity.

\footnotetext{
${ }^{16}$ The oil trade balance is also sometimes used to proxy the sensitivity of a country to changes in commodity prices (e.g. Gruber and Kamin, 2007) and in this context is hence employed as a cyclical, not a fundamental, variable.

${ }^{17}$ Since the stock of NFA is determined by the sum of past CA balances, only the initial (lagged) stock level is included.
} 
Countries with high productivity growth may attract foreign capital flows because they are expected to yield higher rates of return.

\subsubsection{Policy variables}

General government fiscal balance. This variable is generally included in CA models (e.g. Bussière et al., 2006, Chinn and Ito, 2007, Gruber and Kamin, 2007; Cheung et al., 2013), in that there are at least two channels via which the fiscal balance acts (Abbas et al., 2011). On the one hand, as highlighted by the well-known Mundell-Fleming model, based on Mundell (1963) and Fleming (1962), fiscal policy brings about compositional effects on the aggregate demand. In particular, increases in government spending (i.e. increases in the government budget deficit), if skewed toward home (or non-tradable goods) relative to foreign (or tradable) goods, appreciates the RER and worsens the trade, and hence the CA, balance. On the other hand, in the absence of full Ricardian offset from private savings (Obstfeld and Rogoff, 1995), a fall in government saving leads to a fall in aggregate saving, and hence a deterioration in the CA balance, because households fail to adjust personal savings upwards. According to both channels, government budget deficits tend to induce CA deficits, in line with the idea of "twin deficits". A robust finding in the empirical literature is indeed that the fiscal balance is positively linked with the CA, which is interpreted as evidence that households do not fully offset changes in government saving (e.g. Abbas et al., 2011; Phillips et al., 2013). ${ }^{18}$

Openness to international trade. Because macroeconomic policies could also be relevant for CA determination, CA models often include the degree of openness to international trade. In addition to rising globalisation, this variable indeed reflects policy choices such as tariff and non-tariff barriers to trade or industrial policies, which in turn affect goods and services flows (e.g. Cheung et al., 2013; Moral-Benito and Roehn, 2016).

Capital controls. The sign of the relationship of capital controls with the CA is a priori ambiguous (e.g. Chinn and Prasad, 2003; Chinn and Ito, 2007). On the one hand, countries with high restrictions are expected to have relatively limited access to international capital and, therefore, could experience smaller CA deficits. On the other hand, capital controls could reflect the desire to hinder capital flight caused by past CA deficits.

Institutional quality. The legal environment and the level of institutional development are important determinants of saving and investment decisions (Chinn and Ito, 2007; Gruber and Kamin, 2007): they affect the rate of protection of investor rights and hence influence the rate of returns from these activities, in turn impacting the CA balance. High institutional quality in a country could attract foreign investment, hence leading to CA deficits.

Financial development. Recent research has revealed that the CA deteriorates in countries that experience credit booms, with the opposite occurring during credit busts, reflecting either the extent to which financial development better allows for structural consumption smoothing or the financing of temporary, real estate bubbles (e.g. Gourinchas et al., 2001; Mendoza and Terrones, 2012; Aizenman and Jinjarak, 2014; Unger, 2017). Financial crisis dummies

\footnotetext{
${ }^{18}$ The relationship between the government budget balance and investment is less clear. If private and public investment are complementary, an increase in public investment could stimulate private investment. On the other hand, an increase in public dissaving and, hence, in public borrowing, could crowd out private investment. Additionally, the impact of budget deficits on CA balances may depend on how fiscal expenditures are allocated. For example, Chamon and Prasad (2008) argues that the rising private burden of expenditures on health care has contributed to the increase in the saving rate in the 2000s.
} 
are hence at times included in CA models as cyclical or fundamental variables (e.g. Gruber and Kamin, 2007); ${ }^{19}$ similarly, private credit gaps (for example relative to country-specific trends) are also employed either as cyclical or policy variables, in the latter case proxying for financial development (e.g. Coulibaly et al., 2018). ${ }^{20}$ As highlighted, for example, by Chinn and Prasad (2003), Cheung et al. (2013) and Moral-Benito and Roehn (2016), the impact of financial market development and of financial regulation on the $\mathrm{CA}$ is ambiguous. On the one hand, financial deregulation may deepen financial markets and could therefore enhance saving, by reducing transaction costs, offering a wider range of saving products and facilitating risk management, thereby raising the CA balance. On the other hand, financial deregulation may relax borrowing constraints faced by agents and could hence reduce their need for precautionary saving, in turn, fuelling credit-driven consumption and investment growth and thus weakening the CA balance. ${ }^{21}$ Moreover, emerging economies could bypass their under-developed and inefficient financial markets by exporting their excess capital to countries with more sophisticated financial systems (e.g. Ju and Wei, 2010; Barnes et al., 2010). ${ }^{22}$ Improved financial deepening (via a combination of better corporate governance and lower costs of financial intermediation) could hence lower the saving rates in emerging economies and imply a negative relationship between financial development and CA balances.

\subsubsection{Additional technical details}

Non-linearities. In contrast to the aforementioned standard neoclassical theory, Lucas (1990) points to evidence of "uphill" capital flows across countries: in his view, flows to emerging economies have been lower than those predicted by theory because of distortions that lower the risk-adjusted returns to capital. ${ }^{23}$ These distortions include under-developed and imperfect international capital markets or weak institutions. The so-called "Lucas paradox" has been corroborated by more recent empirical studies (e.g. Bernanke, 2005; Obstfeld and Rogoff, 2009; Gourinchas and Rey, 2014). This evidence has led to modelling non-linearities within CA models, for example interacting: a) relative income with policy variables, such as capital openness (Coutinho et al., 2018, Cubeddu et al., 2019; Chinn and Ito, 2007), as the sign of the flows may depend on the degree of capital mobility; and b) demographics with policy variables

\footnotetext{
${ }^{19}$ In addition to the financial crisis dummy, Gruber and Kamin (2007) also includes an interaction term, i.e this dummy variable multiplied by trade openness, in the CA model. The rationale for this is that more open economies are likely to have larger tradable goods sectors and thus be able to adjust their external balances more flexibly in response to financial crises. Furthermore, it is worth emphasizing that in this study the financial crisis dummy is a measure of banking crises, not currency crises. The latter indeed often signal a sharp exchange rate depreciation, thus representing a proximate determinant of the CA rather than a fundamental factor.

${ }^{20}$ Further proxies of financial market development are stock market capitalization, stock market turnover and private bond market capitalization (Cheung et al. (2013).

${ }^{21}$ Empirically, Moral-Benito and Roehn (2016) find that different dimensions of financial deregulation have different effects on the CA. In particular, easing bank entry barriers is significantly and negatively associated with the CA balance, whereas bank privatization and securities market deregulation tend to raise it.

${ }^{22}$ In turn, countries with better financial institutions emerge as the global financial centres, attracting financial capital from all countries, dispensing direct investment around the world and contributing to the so-called "global savings glut" (Bernanke, 2005).

${ }^{23}$ In particular, Lucas (1990) finds that accounting for the role of human capital externalities eliminates the cross-country return differentials. As noted by Alfaro et al. (2008), the former study, however, assumes that these externalities in a given country accrue entirely to domestic producers, such that all knowledge spillovers are local, hence disregarding the presence of international knowledge spillovers.
} 
(e.g. Coeurdacier et al., 2018), since, when countries differ in their ability to borrow over the life cycle and across generations, a common trend of global aging tends to divert capital flows towards advanced economies, which typically have more developed credit markets and a stronger social security system; c) trade openness with other attributes that make a country attractive to foreign capital, such as institutional quality, in that weak institutions may lower risk-adjusted returns to capital in emerging economies (Alfaro et al., 2008).

Country fixed effects. Most papers in the CA modelling literature (e.g. Chinn and Prasad, 2003) argue against the use of country fixed effects in CA models on the grounds that they pick up the impact of slow-moving fundamentals, leaving the bulk of structural crosscountry differences unexplained and providing a weak basis for the computation of CA norms. In particular, given the within-groups transformation required by fixed effects OLS, one cannot exploit the information contained in regressors with no or little variation over time. Not including fixed effects, however, implies that conditional on the fundamentals included in the model, the steady-state level of the CA is zero (Bussière et al., 2010); moreover, this choice is known to significantly penalise model fit. ${ }^{24}$

The persistence of the CA balance. Lagged CA balances are frequently found to be statistically significant (Calderon et al., 2005; Bussière et al., 2006; Ca' Zorzi et al., 2012; MoralBenito and Roehn, 2016), since CA balances are persistent, for example due to habit formation in consumption and savings behaviour. However, the inclusion of lagged values in a CA model would basically imply predicting CAs on the basis of previous-year values, i.e., by including quasi-fixed effects, and hence hinder a normative interpretation of the results.

\subsubsection{A meta-analysis}

In order to detect the relevance of the CA drivers discussed in the literature, we provide the results of a meta-analysis in Figure 3, based on 22 available empirical articles that estimate a CA model, listed in Table A.2 in the Annex, and singling out the explanatory variables that appear most frequently, grouped into the fundamental, cyclical and policy variable categories employed thus far in this paper. The size of the bars in Figure 3 corresponds to the number of times a given variable is included in the baseline CA model of a given paper; the three components of each bar represent the number of papers in which the coefficient attached to the given variable is statistically significant and positive, statistically significant and negative, and statistically insignificant, respectively. Results are not always clear-cut, given that several bars contain the three differently coloured cases.

Amongst all variables found in CA model specifications, income per capita, which, as mentioned earlier, captures the level of economic development of a country, is the explanatory variable that is most diffusely included in CA models (in particular, in 20 out of 22 surveyed papers), with all models pointing to a significant positive relation to the CA balance, when the coefficient is statistically significant. Conversely, the few times income per capita squared is considered, it is found to be statistically insignificant. Different proxies measuring demographic trends, which will be discussed more fully in Section 3.3, are also frequently employed in CA

\footnotetext{
${ }^{24}$ Moral-Benito and Roehn (2016) argues in favour of the use of the correlated-random-effects estimator, which exploits both within-and between-country variation and also allows including country-specific fixed effects. Indeed, the use of between-country variation by this estimator also allows investigating the effect on CAs of structural variables with little (or no) variation over time in a panel setting with country dummies. However, the issue of how to interpret the CA norm remains open.
} 
Figure 3: Explanatory variables most frequently included in CA models

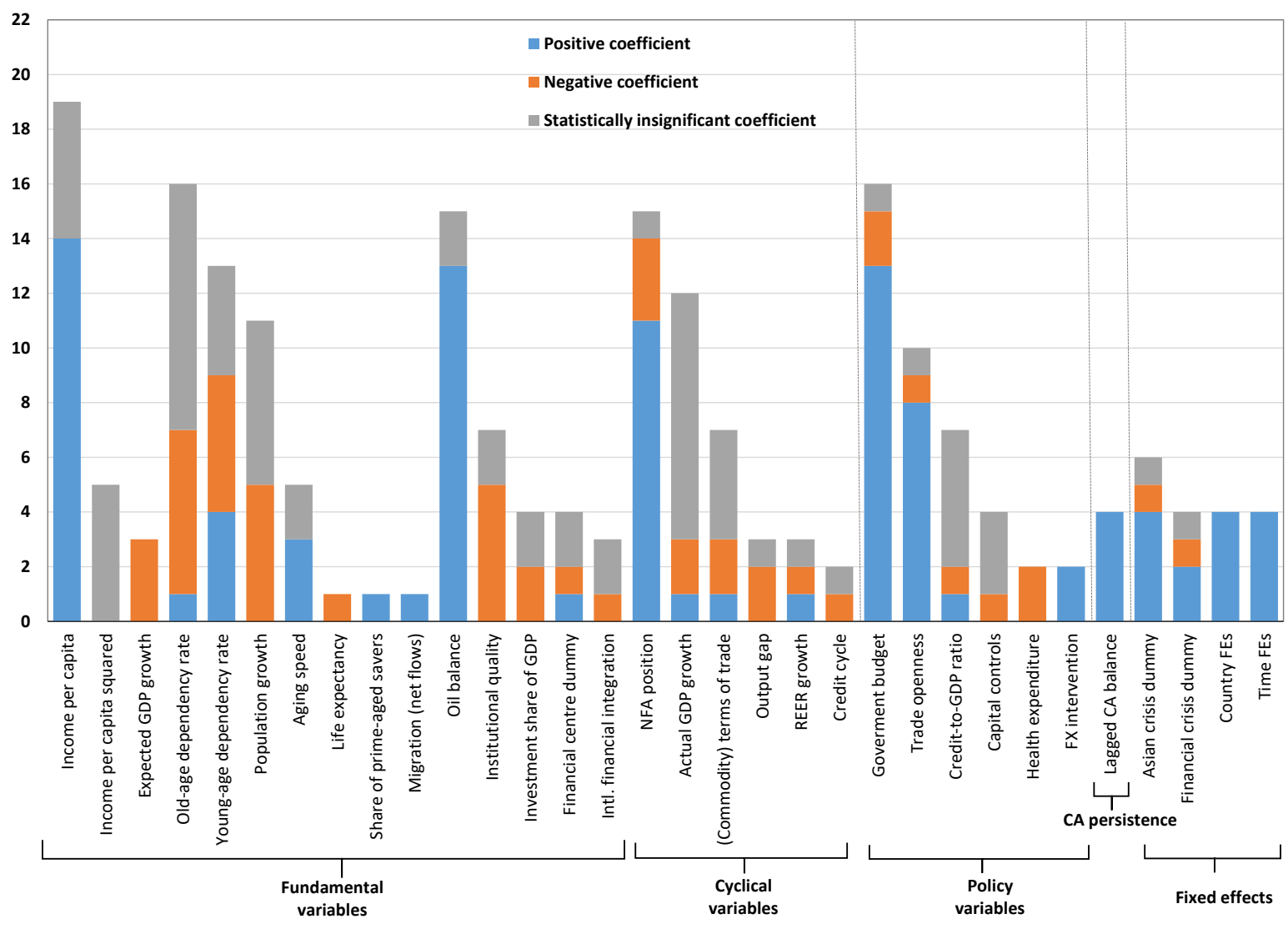

Source: Authors' calculations on a survey of 22 papers, listed in Table A.2 in the Annex.

models, as well as the net oil exporter/importer status of a given country. In general, it is clear that fundamental variables are included more often than cyclical determinants. This is also due to the fact that, as discussed in Section 2.2, a significant portion of the existing literature estimates a CA model on five (or similar)-year averaged data as a means to avoid including variables that measure the business cycle. When considered, a country's NFA position and actual GDP growth are the most commonly included cyclical explanatory variables, where the former is largely significant and mainly found to be positively correlated with the CA balance and the latter is, instead, generally insignificant. Amongst the policy variables, the government's fiscal balance appears in $16 \mathrm{CA}$ models, largely with a positive sign, confirming the empirical literature reported earlier, followed by trade openness, which is included in nearly half of the surveyed papers, again generally displaying a positive sign. Finally, despite their statistical significance, only few CA models include the lagged CA balance and country fixed effects, for the reasons discussed earlier.

In conclusion, the set of explanatory variables that may be included in a CA model is vast, as documented also by the heterogeneous specifications employed in the existing empirical literature. Moreover, the sign and magnitude of the coefficient of a given CA determinant can depend on the country sample and time period under study. Furthermore, in a CA model 
goodness of fit is frequently penalised relative to the normative interpretation of the CA norm estimates, such that the lagged CA balance and country fixed effects are rarely included. To complicate matters further, the uncertainty concerning which variables to actually include in a CA model also extends to the target variable of the model, as the next section will explain.

\subsection{The two channels through which determinants affect the CA}

In principle, it could be appealing to model the two accounting components of the CA (savings and investment) separately, since it allows for the fact that a given determinant may have a heterogeneous impact on savings supply and investment demand. In other terms, it could be intriguing not to consider the CA balance as the dependent variable of a CA model, but rather the savings and the investment rates, separately.

To our knowledge, however, few studies pursue this avenue. An early example is Isard and Faruqee (1998). This study examines the saving-investment balance within a system of separate equations for the CA, saving and investment (all as ratios of GDP), with cross-equation restrictions imposed in the estimation. In particular, each equation includes the lagged dependent variable, whose coefficient is imposed to be the same across the three equations. Moreover, the coefficients of all other fundamental explanatory variables in the CA equation are restricted to be equal to the difference between the corresponding coefficients in the saving and investment equations, while country fixed effects, which enter each equation, are estimated with no constraints. The results of this study point to changes in relative fiscal or demographic positions affecting the saving-investment balance primarily through their effect on domestic saving. Relative income per capita operates roughly equally through both saving and investment, while the effect of the output gap on the CA largely works through its effects on investment. ${ }^{25}$

Another, more recent study, Phillips et al. (2013), i.e. the methodological paper that underlies the old IMF EBA methodology, uses the same set of CA determinants to assess their relationship with savings and investment in two separate equations, but purely as a robustness check. $^{26}$ The study concludes that the majority of the significant variables in the CA regressions appears to operate through the savings channel. ${ }^{27}$

Even more recently, Coulibaly et al. (2018) examines the determinants of saving, investment and the CA separately, but using the same set of explanatory variables. The main finding is again that the main channel via which the CA determinants operate is the savings channel. ${ }^{28}$

De facto, however, modelling the investment and savings channels separately in order to then yield a consistent CA norm is problematic. This is due to the observed statistical discrepancy between the official data on CA and $S-I$ for several countries (Fig. 4), implying that Equation 5 does not tightly hold in practice. Although the quality of statistics has significantly improved

\footnotetext{
${ }^{25}$ In the same year, Higgins (1998) estimated three separate regressions for saving, investment and the CA balance, finding a significant role for the investment channel, yet the specification was very parsimonious, only including demographic factors, labour productivity growth and the relative price of investment goods.

${ }^{26}$ Chinn and Prasad (2003) adopt the same sensitivity analysis approach.

${ }^{27}$ In particular, the investment channel is found to be the dominant one for only three explanatory variables, namely output gap (due to the fact that investment is highly cyclical), expected GDP growth (which has been found to be a significant determinant of business investment, for example, in Bussière et al., 2015), and the VIX, i.e. the weighted average of the implied volatility of a subset of call and put options on the S\&P index, yet only for non-reserve currency countries (the interaction between foreign flows and uncertainty affects investment).

${ }^{28}$ The two exceptions of variables which are also statistically significant in the investment equation are GDP growth (similarly to Phillips et al., 2013) and GDP per capita.
} 


\section{Figure 4: The discrepancy between the CA balance and the S-I gap by country grouping \\ (annual averages across countries; percentages of GDP)}

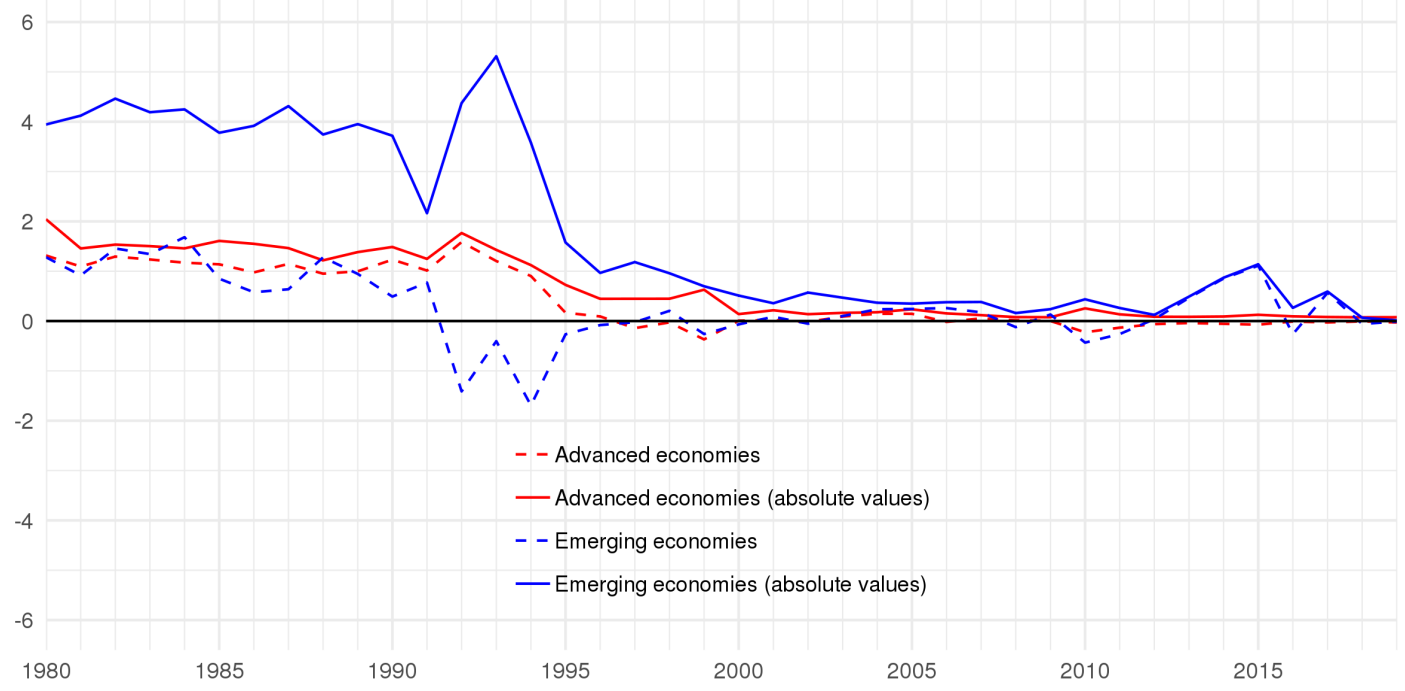

Source: Our calculations on IMF World Economic Outlook data.

Notes: See Table A.1 in the Annex for a list of the 57 (advanced and emerging) countries considered herein.

over time - as testified by the decreasing discrepancy, in absolute value terms, since the 1980s - for emerging economies the gap is currently still far from negligible.

This statistical discrepancy could explain why the majority of existing studies targets the CA position directly and why the residual literature has either imposed coefficient restrictions, as in Isard and Faruqee (1998), in order to guarantee consistency, or has resorted to the estimation of savings and investments separately simply as a robustness check to assess the relative relevance of the two channels for a given determinant.

\subsection{Measuring the key explanatory variables}

Measurement and data availability are key constraints in setting up a CA model, which condition the set of variables to be included in the specification. Several determinants cited in Section 3.1 are indeed hard to measure, especially those that attempt to capture less standard variables, which in turn reflect more recent, global trends. In this section we provide some examples of key CA drivers and the measurement issues affecting them, which often have no clear solution.

One prominent example is demography. Standard "static" measures of demographic factors (e.g. Ca' Zorzi et al., 2012; Lane and Milesi-Ferretti, 2012; Phillips et al., 2013), associated with the age composition of a country's population, in turn recently driven by declining fertility rates, are: the old-age dependency ratio, constructed as the ratio of people older than 65 years to the working-age population aged between 14 and 65 ; the youth dependency ratio, constructed as the ratio of young people under 14 to the working-age population aged between 14 and $65 ;^{29}$

\footnotetext{
${ }^{29}$ These two variables are often considered jointly in an overall age dependency ratio (e.g. Coulibaly et al., 2018.
} 
population growth, which partly proxies the share of young people. ${ }^{30}$ Higgins (1998) uses a loworder polynomial to represent 15 population age shares, a technique, introduced by Fair and Dominguez (1991), which has the advantage of capturing the information contained in the entire age distribution while maintaining a parsimonious parameterization. Instead, based on Dao and Jones (2018), Cubeddu et al. (2019) introduces a less common static demographic factor (the share of prime-aged savers, aged 45-64, as a proportion of the total working-age population), as well as variables aimed at capturing the dynamics of demography, which measure the role of increasing life expectancy, in turn driven by longevity or old age survival risk, via the following proxies: the life expectancy of prime-aged savers and its interaction with the future (i.e. 20-year ahead) old-age dependency ratio. ${ }^{31}$

Strictly related to demographics is migration, another variable that is hard to measure (Coulibaly et al., 2018), even when abstracting from illegal migration. A migrant stock is defined as the total number of international migrants present in a given country at a particular point of time. A migration flow is defined as the number of persons arriving or leaving a given country over the course of a specific period of time. As documented in Abel (2013), international comparisons on migration flow data are difficult to conduct. Indeed, similarly to trade flow data, movements can be reported by sending or receiving countries; when data collection methods or measurements in countries differ, the reported mirror data do not match. Moreover, in many countries data collection systems for migration flow data do not exist or are partial. Conversely, stock data are more widely available, both across time and countries. For these reasons, to proxy for migration flows some studies (e.g. Docquier et al., 2014) rely on the difference between two successive bilateral stock matrices. These measures are good estimates of the long-term flows of permanent migrants, but they understate the inflow of new migrants in that between the two periods some migrants present in the first period may die, return or migrate towards another country. To overcome this drawback, Abel (2013) puts forward a new method that estimates migrant transition flows between two sequential migrant stock tables, using data on population, i.e., the number of births and deaths. Coulibaly et al. (2018) employs this latter dataset to compute net immigration flow rates given by the difference between immigration and emigration flows per population of the host country. The study also considers net immigration stock rates, computed as the difference between immigration and emigration stocks as a percentage of the host country population. Indeed, since former migrants may continue to remit to their home country, relying on migration stocks rather than flows is more relevant to reflect the influence of such remittances on the CA, in that they imply the settlement of migrants in host countries over a relatively long period. The proxies employed in Coulibaly et al. (2018) may hence be the most appropriate to be included in a CA model. However, to our knowledge, these data are not publicly available.

By considering several databases - namely the IMF World Economic Outlook, the World Bank World Development Indicators and the United Nations World Population Prospects

\footnotetext{
${ }^{30}$ The natural rise in labour force has also been proxied by the rate of natural increase in population, i.e. the rate of population change in the absence of migration, obtained by the difference between the death and birth rates (Coulibaly et al., 2018).

${ }^{31}$ The latter proxies replace the more standard measure of the aging rate, defined as the expected change in the old-age dependency ratio in the future, constructed as the difference between the projected age dependency ratio in year $t+20$ and the actual ratio in year $t$ (Phillips et al., 2013). The latter variable has the shortcoming of confounding different forces in one indicator, namely changes in longevity, cumulative fertility changes and variations in cohort sizes.
} 
datasets -, coverage of the various demographic and migration proxies discussed thus far, for the years between 1980 and 2018 and for the 57 countries listed in Table A.1 in the Annex is almost complete, with the exception of Taiwan for a couple of proxies. However, the net migration rate is computed on data on net international migration flows and on the differences in overall population growth and the increase in its natural rate (i.e. the portion of population change determined exclusively by births and deaths), thereby suffering from the afore-mentioned drawbacks. Moreover, only few of these variables are currently available for 2019, implying lack of timeliness, but given that these measures vary little over time this is not a significant issue. Rather, it becomes important to select the most relevant demographic proxy or proxies, as they are highly correlated amongst themselves, and including the bunch of them together in a CA model may not be the most appropriate solution in the econometric sense, as later discussed.

Linked to demographic trends is a policy variable that measures the type or degree of generosity of a given country's pension system. In order to calibrate social security systems, Coeurdacier et al. (2018) innovatively collects information on pay-as-you-go systems across many countries. ${ }^{32}$ For each country, the authors construct a schedule of replacement rates for an average income earner, as a function of the number of years of contribution. Taking the difference between country-specific ages of retirement and labour market entry to proxy for the number of years of contribution, they thus obtain an official replacement rate. However, one also needs to account for the actual coverage of social security programmes, which varies cross countries. ${ }^{33}$ Lower coverage translates into lower contribution and replacement rates. For this reason the scholars adjust for (the mean of) two different proxies of coverage: the percentage of retired receiving benefits and the percentage of the working age population contributing to pensions. ${ }^{34}$ Although very original, the final measure of replacement rates is time-invariant, when it is known that since the 1980s many countries amongst those listed in Table A.1 underwent significant pension reforms and more may be in the pipeline.

As regards other potential CA determinants, in order to measure (household) credit constraints, Coeurdacier et al. (2018) uses information on aggregate gross household debt. An issue with this proxy is that credit aggregates do not allow disentangling supply and demand (Bernanke and Gertler, 1995). The recent literature has therefore tried to improve identification using micro data, in particular direct, survey-based information on the limits of credit availability. ${ }^{35}$ Credit access conditions refer to the entire pool of possible borrowers and therefore these data are not subject to sample bias on granted loans as is the case for aggregate debt data. However, cross-country survey data on financial constraints are limited in terms of time and country coverage, which implies either: (i) resorting to a time average, losing out, however, on significant fluctuations over time, for example during the global financial crisis or the sovereign debt crisis; or (ii) complementing the missing countries and years with aggregate debt data.

Another non-standard variable is found in Moral-Benito and Roehn (2016), which employs publicly available data sourced from Abiad et al. (2010) in order to capture financial regulation. In particular, the latter database covers seven dimensions of financial policy reform for 91

\footnotetext{
${ }^{32}$ These data are drawn from the Social Security Administration website.

${ }^{33}$ In emerging economies, for instance, typically few workers contribute to the official system and qualify for any benefits.

${ }^{34}$ These data are sourced from ILO's World Social Security Report. The former proxy is typically higher than the latter, reflecting the existence of universal minimum benefits.

${ }^{35}$ For example, for Italy see Guiso and Parigi (1999), Gaiotti (2013), Giordano et al. (2019) and Giordano et al. (2021).
} 
economies over the period 1973-2005: credit controls; interest rate controls; entry barriers; State ownership in the banking sector; financial account restrictions; prudential regulation and supervision of the banking sector; securities market policy. Along each dimension, a country is given a score on a graded scale from zero to three, with zero corresponding to the highest degree of repression and three indicating full liberalization. Moral-Benito and Roehn (2016) shows that the different dimensions of financial regulation can have opposing effects one the CA, as already discussed in Section 3.1, such that it makes sense to consider them all jointly. Relative to the more standard indicators of financial development, such as credit gaps, which are likely to be endogenous to savings and investment decisions, these measures of regulatory settings are less likely to suffer from this bias. Furthermore, regulation is under the direct control of policy-makers and can be hence considered strictly as a policy variable. However, like all codings that convert qualitative information into a quantitative proxy, this measure suffers from a large judgement bias.

Finally, as mentioned in Section 3.1, financial centre dummies are sometimes included in CA models in order to capture measurement biases for a few economies with large gross foreign investment positions. However, these measurement biases may change in sign and size over time, since they vary with many factors, including net equity and debt positions, inflation differentials, differences in dividend policies, etc. For this reason the EBA methodology, which initially included financial centre dummies (Phillips et al., 2013), then dropped them in the later update (Cubeddu et al., 2019). ${ }^{36}$ In Section 4 we will return to connected mismeasurement issues.

In conclusion, the researcher faces a measurement trade-off: whereas for standard variables country-specific and time-varying measures are available for a large number of countries, in order to take into account the most recent developments of the CA literature, a feature which is desirable in setting up state-of-the-art CA models, data are, however, far less comprehensive. Moreover, providing there is a theoretical justification to including a given variable in a CA model and providing the data are available, which proxy should one use? Should one include all measures in the same regression, which is the IMF EBA approach, or should one select only the statistically significant proxies, also to avoid multicollinearity? The next section discusses possible model selection methods in this respect.

\subsection{Selecting the core explanatory variables}

As discussed thus far, there is no unambiguous prior theory for the selection of the explanatory variables to be included in a CA model; those proposed as CA drivers in previous studies cannot be excluded a priori. Yet, it is not necessarily optimal to include all possible variables as there is indeed a trade-off between using potentially redundant variables, which result in less precise coefficient estimates, and a potential omitted variable bias, which could distort estimates if the omitted variable is correlated with the other regressors. Hence, model uncertainty hampers consensus on the CA determinants to be included in the $X$ vectors of Equation 6 .

This model uncertainty may be handled econometrically, for example by using Bayesian

\footnotetext{
${ }^{36}$ As an alternative to these dummies, Cubeddu et al. (2019) introduced outside-of-model adjustors for measurement issues when empirical estimates of retained earnings and inflation measurement biases consistently point to sizable mismeasurement, when there is evidence of persistent differences between a country's financial account and changes in its NFA position and when both of the above point in the same direction.
} 
model averaging (BMA) techniques. ${ }^{37}$ To our knowledge, the studies applying this formal "horse-race" method to appropriately specify a CA model are only a handful, namely Ca' Zorzi et al. (2012), Moral-Benito and Roehn (2016) and Desbordes et al. (2018). This methodology aims at detecting systematic empirical regularities, whereas precisely identifying causal relationships would require a more structural approach that cannot handle this amount of data, and which anyhow goes well beyond the scope of CA modelling for policy purposes. In particular, BMA involves the estimation of all possible sets of variables, assigning to each set a posterior model probability of being "true" based on Bayesian inference, and then the computation of a weighted average of all the estimates for a given coefficient in a statistically optimal way. Inference can then be based on the whole universe of candidate models, by considering not only the uncertainty associated to the coefficient estimate conditional on a given model, but also the uncertainty of the coefficient estimate across different models. In practice, via BMA different subsets of so-called "auxiliary" regressors (i.e. the potential determinants of the CA in our case) can be excluded from the model to improve, in the mean squared error sense, the efficiency of the "focus" parameter estimates (i.e. the coefficients attached to the variables that necessarily one wants to include in the model). As is standard in BMA applications (Magnus et al., 2010; Giri et al., 2019; Giordano, 2021), a variable can then be deemed to be a relevant CA driver when its posterior inclusion probability exceeds the threshold value of 0.5 across most specifications.

An alternative method that is capable of dealing with a very large number of predictors is the least absolute shrinkage selection operator (LASSO), put forward in Tibshirani (1996). This method provides a systematic, data-driven approach to variable selection, where a penalty on the absolute size of coefficient estimates is imposed and some coefficients are set to zero as a result, hence excluding the corresponding variables from the model. When applying this method, a choice however must be made concerning the level of penalisation. There are several possibilities, for instance based on the application of standard information criteria (Akaike, Bayesian, etc.) or on a process called "cross-validation", which repeatedly subdivides the sample into smaller "training" and "validation" datasets, selecting the penalisation parameter that shows the best performance (a function of prediction errors) on the latter set. A drawback of LASSO is that the penalization procedure shrinks the size of the estimated coefficients attached to the variables that remain in the active set (Ng, 2013; James et al., 2017). This feature, acceptable for prediction purposes, is instead unpalatable for models with important normative implications, as it reduces the economic significance of the included explanatory variables. Moreover, conducting standard statistical inference, such as hypothesis testing, is complicated in the context of LASSO techniques. In sum, the LASSO procedure is best suited for prediction purposes, when a very large number of possible predictors must be considered, and less so for the estimation of a CA norm, where the set of potential explanatory variables, in turn guided by economic theory, is high but still manageable.

Finally, once the CA drivers are appropriately selected and the CA model is set up, the model needs to be accurately estimated, as discussed in the next section.

\footnotetext{
${ }^{37}$ See Magnus et al. (2010) and Moral-Benito (2012) for a formal, general derivation of the BMA method.
} 


\subsection{The econometric estimation of a CA model}

Using a panel dataset on a wide sample of economies, as opposed to single country regressions, is now standard practice when estimating CA models. Exploiting both the time and the crosssection dimensions indeed increases sample size and raises the power of statistical tests, as well as achieving more robust estimates.

However, using a unique panel equation for calculating CA norms hinges on the very strong assumption that the same behaviour of economic fundamentals applies to all countries, which often include both advanced and emerging economies. To some extent, this is a desirable property: the economic fundamentals that drive CA balances in the long term should be the same across countries, if, looking forward, emerging economies should behave more like advanced economies. In other terms, estimating a single equation for all countries allows smoothing the impact of individual countries' transitional dynamics (Bénassy-Quéré et al., 2008). However, the exact relation between the dependent variable and each of its drivers may differ across countries.

Moreover, the variables in the model are not necessarily stationary in the long time-spans usually considered. The construction of the explanatory variables as deviations from world averages can induce stationarity, but this is not always the case. Standard Ordinary Least Squares (OLS) is hence not the correct setting in the presence of non-stationary variables.

Another technical issue that a panel setting raises is that of cross-section dependence (CSD; e.g. Bussière et al., 2010). Indeed, when both the number of countries and time periods are large, cross correlation of errors may emerge, due to omitted, unobserved common effects to all countries, such as global demand and supply shocks. In the specific CA model setting, the case for CSD is especially compelling, given the fact that most explanatory variables are expressed relative to a weighted average of partner countries. Conventional panel estimators such as fixed or random effects can result in misleading inference and even inconsistent estimators, depending on the extent of CSD and on whether the source generating the CSD (such as an unobserved common shock) is correlated with the regressors (Chudik and Pesaran, 2015).

Allowing for various forms of country heterogeneity in the panel estimation procedure even in the presence of non-stationary variables is however possible owing to the latest-generation panel cointegration techniques. Moreover, these recently developed techniques can also correct for the potential CSD bias. Indeed, one possible solution is to adopt the common correlated effects mean group (CCEMG) estimation procedure (Kapetanios et al., 2011), already employed in the context of equilibrium REER estimation, for example, in Fidora et al. (2021) and Giordano (2020). The appropriateness of this estimation technique is due to the fact that: (i) it accommodates for both stationary and non-stationary cointegrated variables; (ii) it allows for heterogeneous slopes, which is of paramount importance given the vast country heterogeneity in the panels underlying CA models; (iii) it includes cross-section averages of the dependent and explanatory variables in order to tackle CSD. However, this procedure generally includes country fixed effects, necessary in the case of REER misalignment estimation due to the general index number nature of the dependent variable (Giordano, 2021), but which are not appealing in the case of CA model estimation, as discussed in Section 3.1. ${ }^{38}$

\footnotetext{
${ }^{38}$ Another possible estimation technique is the correlated-random-effects (CRE) estimator used by Moral-Benito and Roehn (2016), but it requires the inclusion of country fixed effects to account for unobserved heterogeneity. The CRE estimator is a maximum likelihood estimator, which allows it to be combined with a BMA technique
} 
Another econometric issue is reverse causality. Generally, in a CA model feedback from CA developments to the regressors is not allowed. Despite its relevance, this issue is typically neglected in the literature mainly due to the lack of instrumental variables (Chinn and Prasad, 2003). It is indeed difficult to find a set of variables related to the CA determinants but not directly related to the CA. Moreover, lagged levels of the regressors, as used for example in Coutinho et al. (2018), are only weak instruments, given the persistence of most variables. One partial exception is Cubeddu et al. (2019), which employs instruments for two CA determinants, namely fiscal policy and foreign exchange intervention. ${ }^{39}$ However, first-stage estimation results are not provided and is hence not possible to assess the validity of the chosen instrumental variables; moreover, they only address two out of many explanatory variables, for which endogeneity may still be a concern. Reverse causality in CA regressions and precisely identifying causal relationships would indeed require a more structural approach that cannot handle the amount of data underlying the CA model estimation. This aim, hence, goes beyond CA modelling for policy purposes.

\section{Recent and future challenges to CA modelling}

In addition to the mainly technical or data-driven issues discussed thus far, recent trends in the global economy have further complicated CA modelling. In general, CA models frequently lead to large residuals, despite their careful set-up and estimation; this has been attributed to "a combination of structural distortions, measurement biases, and country fundamentals that are not explicitly modelled" (Cubeddu et al., 2019; p. 34). In recent years measurement biases in particular have been exacerbated due to the increasing importance of various economic phenomena, not always adequately represented by the existing statistical standards. In this section we discuss the challenges posed by several recent trends, as well as by the global shock due to the Covid-19 pandemic.

\subsection{The impact of global firms on the trade and income balances}

The growing role of MNEs has, among other things, a large impact on balance of payments statistics (see, for example, Di Nino et al., 2020). Given the topic of this paper, here we focus

to address model uncertainty in the selection of the explanatory variables of the CA model. While it allows accommodating regressors' endogeneity with respect to the permanent component of the error term (i.e. country fixed effects), it is, however, based on the assumption that the explanatory variables are exogenous with respect to other shocks.

${ }^{39}$ In particular, fiscal policy is instrumented using lags for relevant global factors (world real GDP growth, world output gap, world cyclically-adjusted fiscal balance and global risk aversion, which is proxied by the U.S. corporate credit spread), as well as country-specific features (lagged GDP per capita, lagged output gap, the exchange rate regime and a democracy index ranking). For foreign exchange intervention various instruments are employed: a measure of global accumulation of reserves, capturing what is known in the reserve accumulation literature as the "keeping-up with-the-Joneses" effect, or the desire of countries to maintain foreign exchange liquidity (for precautionary motives) at a par with peer emerging market countries (excluding own reserve accumulation for each country); a measure of reserve adequacy linked to M2, which is defined as (M2-reserves)/GDP relative to the average emerging market group; and an emerging market and developing economy dummy to capture the tendency of emerging markets and developing economies to accumulate reserves as part of their export-led growth strategies. The instrumentation is done for identification purposes only (i.e. to accurately estimate the coefficient of the policy variables). When calculating policy gaps as described in Section 2.2, the model is in fact evaluated at the actual value of the policy variables. 
solely on the CA, although naturally the ever increasing presence of MNEs has also affected financial account statistics. MNEs' activity can imply at least four different phenomena that directly affect the computation of the CA balance (Avdjiev et al., 2018).

The first refers to the relocation of production, which $(a)$ can be shifted to a foreign subsidiary via offshoring or $(b)$ can be outsourced to a company abroad that produces goods on the MNE's behalf, according to a process known as "processing" or "contract manufacturing", which has strongly increased in importance in key economic sectors in recent years. ${ }^{40}$ These cross-border manufacturing arrangements can affect the trade-in-goods component of the CA. Indeed, in case $(a)$ the imports and exports of goods no longer show up in the MNE's home country, but in that of the foreign subsidiary; the profit earned by the latter is then transferred to the former via the primary income component of the CA. As a result, the home country's CA balance does not change relative to a pre-offshoring scenario, but its composition does. In case (b), according to the BPM6, during the production process the ownership of the inputs remains with the MNE and hence no trade flows are recorded in the contractor country's balance of payments (with the exception of an import by the MNE of manufacturing services from the foreign company that is producing the good). The sale of the final products to third countries is recorded as the contractor country's exports, thereby not affecting the CA balance of this country any differently relative to a situation in which the goods were exported directly. ${ }^{41}$

A second consequence for the CA balance arises as a result of the increased tendency of MNEs to move the location of their headquarters to financial centres or in general to countries according to tax and corporate governance considerations in a process called "redomiciliation" or "corporate inversion". These operations do not generate any additional real economic activity in the new headquarters' country, but change the attribution of income across countries. This phenomenon can have large effects in terms of magnitude and volatility of official balance of payments statistics, which become especially visible in those economies where MNE transactions and balance sheets are large relative to the size of the domestic economy. A prominent example is provided by Ireland where the relocation of foreign MNEs' headquarters to the country in recent years brought on an increase in Ireland's receipts of investment income, leading to an overstatement of this country's net primary income balance and hence of the CA balance (e.g. Tedeschi, 2018).

A third aspect is related to the employment and mobility of intellectual property (IP), an intangible asset including research and development, copyrights and computer software, which has markedly increased in importance in the context of the global diffusion of knowledge-based economies (e.g. Moulton and van de Ven, 2018). IP products are non-rival goods, meaning that MNEs can freely use their IP anywhere they operate at zero marginal cost. According to the BPM6, the remuneration of intangible assets (i.e. fees and royalties paid by a user of IP products to the foreign owner of these goods) is recorded as an import/export of services and the booking of these flows depends on the location of the economic ownership of IP. Whereas it takes time and significant disinvestment to relocate the physical production of goods in

\footnotetext{
${ }^{40}$ See, for example, the case of the pharmaceutical sector in Italy (Allione et al., 2020).

${ }^{41} \mathrm{~A}$ further practice related to MNEs that may affect official CA statistics is "merchanting", i.e. the process whereby a company purchases a good from an entity resident abroad and subsequently sells it to a buyer in a third country without the good crossing the border of the country where the merchant is based. If these transactions involve foreign entities belonging to the same group, their pricing has a decisive impact on the amount and location of profits booked (Di Nino et al., 2020).
} 
factories, IP products are far easier and cheaper to relocate and they are also harder to value at market prices. They can therefore be shifted around the world also in order to minimise tax expenditure and, more in general, foster profits (e.g. Accoto et al., 2021). The relocation of IP across countries via MNEs can change the geographical location where exports and income are recorded. For example, the recent shift of IP to Ireland indeed affected the country's net exports: in particular, the Irish resident companies started charging foreign companies fees to produce the patented products, leading to an increase in service exports and since the Irish resident companies stopped paying fees for use of IP a decrease in service imports was also recorded.

Linked to the impact of MNEs on the CA statistics is also the increase in external financial openness since the mid-1990s, only partly interrupted by the 2008-09 global financial crisis (GFC; Lane and Milesi-Ferretti, 2018), which has implied that primary income flows, and, in particular, investment income flows, a component of the CA balance as reported in Section 2.1, have also grown in size, leading to what has been defined as the "financialization of the CA". The measurement of the investment income balance according to official BPM6 standards differs from the standard economic concept of accumulation of real net external wealth on an ultimate owner basis in at least two respects, as thoroughly discussed in Cubeddu et al. (2019). First, the statistical treatment of retained earnings (i.e. profits retained in the foreign affiliate) is different for FDI and portfolio investment, the two main investment items, and is not always attributed to the ultimate owner. In particular, while for FDI equity both paid-out dividends (i.e. profits distributed to the direct investor) and retained earnings are recorded in the CA income balance, for portfolio equity only paid-out dividends are recorded. ${ }^{42}$ Second, although all forms of income in the balance of payments are recorded in nominal terms, the recording of interest income in this manner departs from the economic notion of real income and the income balance is therefore biased by inflation. The $\mathrm{CA}$ balance hence reflects these measurement issues concerning the investment income balance, in turn due to the existing statistical standards, and the accuracy of CA modelling is penalised as a result.

To sum up, MNEs can affect the recording of CA statistics in different directions, impacting either the trade balance or the primary income balance or both. To our knowledge no paper has ever attempted to model the trade balance and the income balance separately, also due to the difficulty of gauging the cyclical vs. structural determinants of the latter, as discussed in Section 2.3. The inclusion of dummies, such as financial centre dummies, in the CA model has partly attempted to tackle this measurement bias in those countries for which it is most relevant, but the recent literature has avoided this approach, as discussed in Section 3.3, as too broad-brush and even distorting. Given the current official statistical framework, one rough way of accounting for all these phenomena could be to investigate the significance of a measure of the weight of foreign-owned firms in a country's CA model.

\subsection{The "corporate savings glut"}

Another recent trend which has further complicated CA modelling is the so-called "corporate savings glut". According to Chen et al. (2017), whereas in the 1980s most of global investment was financed by household saving, nowadays nearly two-thirds of investment is funded by corporate saving, due to a widespread rise in the share of corporate profits that mirrors

\footnotetext{
${ }^{42}$ Retained earnings referring to portfolio equity are reflected in IIP valuation changes only.
} 
the global decline in the labour share. A similar recomposition has not been recorded for investment, implying that non-financial corporations have generally shifted from net borrower to net lender positions, hence contributing to a secular decline in domestic investment. Dao and Jones (2018) notes that the rise in corporate saving and net lending, in turn due to rising profitability, lower financing costs and reduced tax rates, has been most pronounced in countries with persistent CA surpluses, such as Germany and the Netherlands, but it has also affected some emerging economies. Theoretically, the standard model of intertemporally optimizing households with rational expectations predicts that the saving behaviour of the non-household sectors, i.e. the government and the private corporate sector, has no influence on total saving and on the CA (Obstfeld and Rogoff, 1995). To the extent that households own domestic corporations, household saving behaviour should offset differences in corporate saving. However, a rise (fall) in corporate saving leads to a higher (lower) CA if private households fail to see through the "corporate veil", i.e. if higher (lower) corporate saving is not fully offset by lower (higher) household saving. This mechanism is conceptually similar to the non-Ricardian saving behaviour by households as a reaction to changes in the government budget discussed in Section 3.1. One possibility to take this trend into account is to include corporate saving in a CA model; to our knowledge this has only been done in Behringer and van Treeck (2018), which finds statistically significant results, yet not for normative purposes.

\subsection{The current COVID-19 pandemic: a global shock to CA balances}

At the time of writing this paper, the global economy was hit by the COVID-19 pandemic, which, amongst manifold effects, has marked large shifts in CA balances, driven by shocks to trade, oil prices, tourism and remittances. The pandemic, although global, has hit individual economies in a heterogeneous fashion, according to the composition of their trade flows, the degree of reliance on tourism, the relevance of immigration, amongst several factors. It has also triggered concerns over a possible dismantling of global supply chains and of the strengthening of protectionist measures and of anti-immigration policies. It is far too early to predict the long-lasting economic effects of this pandemic. However, some qualitative considerations on how the pandemic may affect CA model estimation are useful even at this early stage.

The first issue concerns the uniqueness of the CA norm. Will it still be meaningful to estimate average coefficients over a time-span since 1980 as is commonly done now (e.g. Coutinho et al., 2018; Cubeddu et al., 2019) in order to derive one, medium-term CA "equilibrium" value? Or, providing all the necessary data become available (which occurs with up to a two-year delay according to the variable), will the post-2020 norm need to be estimated separately from the pre-2020 benchmark, as a reflection of a "new normal"? In other terms, will the COVID-19 outbreak, which is still ongoing at the beginning of 2021, lead to structural changes that will permanently affect CA norms, in turn leading to a new equilibrium? In particular, CA norms may be affected by such factors as changing global financial conditions, the extent of "scarring" effects of the pandemic, erosions in global value chains, shifts in demographics, changes in desirable fiscal positions. Given the high uncertainty, at the moment it is not possible to answer this question. However, robustness checks reported in Fidora et al. (2021), for example, concerning equilibrium REER estimation, provide evidence that the dramatic GFC in 2008-09, followed by the so-called Great Trade Collapse (GTC), did not represent a significant structural 
break (providing this crisis episode is correctly tackled econometrically). ${ }^{43}$ Similarly, the IMF's CA model is estimated over the whole period since 1980, suggesting the absence of a structural break due to the GTC. This may, hence, be the case also for the COVID-19 pandemic, although the current crisis is already displaying significant differences relative to the GTC, for example as concerns to what extent services trade is affected, and the GTC therefore may not be an appropriate benchmark.

The second issue concerns the changing importance of the CA drivers to be included in a CA model. It is reasonable to expect the economic relevance of several regressors, discussed in Section 3.1, to vary relative to pre-COVID19 times. This may be the case, for example, of oil or more in general commodity trade dependence, trade openness and the government budget, which may increase their contribution to the definition of the CA norm, and of migration flows, which may instead decrease. The outcome depends very much on how transitory or permanent current COVID-19 developments turn out to be. It may also be necessary to explicitly include new explanatory variables in the CA model, such as public and private health expenditure, the generosity and resilience of social security systems, the reliance on foreign intermediate and capital inputs in total production or corporate savings. ${ }^{44}$ Finally, it becomes even more important to disentangle cyclical from structural factors in the evolution of external imbalances in order to address sustainability issues, but this distinction, which was already challenging prior to the pandemic, may become even harder to undertake. For example, the uncertainty surrounding the output gap of a given economy, already high in normal times, is even larger at the current juncture.

Third, the measurement of certain key CA drivers may become more demanding. For instance, given the documented risk of rising protectionist measures introduced by some countries as a reaction to the pandemic, proxying tariff and non-tariff trade barriers with a given economy's trade openness may not be satisfactory anymore. More direct, or even microfounded, measures of trade restrictions may be required, albeit posing country and time coverage issues. To a certain extent, Giordano (2021) provides some reassuring evidence, contradicting this need. This study, focused on REER equilibrium estimation, employs the so-called "phi-ness" indicator of trade, put forward by Head and Ries (2001), as a measure of the level of trade impediments for a given country, derived from bilateral trade flows according to a gravity equation. The correlation between the phi-ness indicator and trade openness is found to be high, hence suggesting that the trade openness variable may not be such a poor proxy of trade restrictions.

Whatever considerations may be made at the current stage, it is highly likely that taking into account the implications of increasing multinational activity and the COVID-19 outbreak in the context of CA models will become the new, major challenge for the measurement and assessment of external imbalances in the immediate future.

\footnotetext{
${ }^{43}$ As reported in Section 3.5, the CCEMG procedure, used in Fidora et al. (2021), employs cross-section averages of both the dependent and explanatory variables in order to control for global shocks, such as those mentioned.

${ }^{44}$ As concerns the latter variable, the COVID-19 crisis could interrupt the afore-mentioned rising trend in corporate saving in the short run due to the decline in firm revenues. On the other hand, the COVID-19 shock could strengthen corporate saving in the long run, as corporates may well aim to restore their liquidity and equity capital buffers to be more resilient in the face of future shocks.
} 


\section{Conclusions}

The measurement of external (im)balances, and in particular those referring to the CA, is crucial for surveillance and policy-making. However, when setting up a CA model, the researcher faces manifold modelling and measurement choices. This paper has summarised the most relevant issues in our view, concerning the selection of the both the dependent and explanatory variables, their measurement and the econometric estimation of the final model. These choices are not innocuous, as resulting $\mathrm{CA}$ imbalances for a given country may significantly differ according to the choices adopted, as already found in the context of REER misalignment estimation (Fidora et al., 2021; Giordano, 2021).

This paper hence raises many issues, which are more often than not left open, given that the researcher building a CA model needs to find an appropriate solution according to her purpose. However, some general conclusions may be drawn. Whereas the CA balance is the most tractable dependent variable of a CA model, as opposed to its two accounting components (the savings rate and the investment rate), also due to statistical discrepancies in official data for many emerging economies, the choice of the CA determinants to be included and the best proxies to be employed very much depends on (high-quality) data availability. Recently developed model selection techniques, such as Bayesian model averaging, may help pinpoint the most meaningful CA drivers, and last-generation panel cointegration techniques may help tackling country heterogeneity, non-stationarity and exposure to common shocks in the cross-country data generally employed in order to accurately estimate the CA model.

Given that modelling uncertainty is anyhow vast, the set-up of a combination of various approaches and models allows testing the robustness and consistency of the resulting estimates. In this paper, we have only discussed one possible approach, but complementing the CA model with a model for direct REER misalignment estimation, such as the aforementioned BEER model, for example, would be advisable, in order to derive consistent information of overall external imbalances. In this respect, the acknowledgment and the communication of large uncertainty surrounding each point estimate of a CA imbalance is also crucial.

In addition to technical issues, recent trends in the global economy have further complicated CA modelling. These trends concern the increasing role played by MNEs, whose taxminimization practices in IP product management, for example, may lead to significant distortions on CA balances; the so called "corporate savings glut" may similarly affect CA balances, in a way that may be hard to capture in conventional models. Currently, the COVID-19 outbreak has posed an additional, unexpected challenge, which may affect the choice of the variables to be included, their best proxy, their economic relevance, as well as their "cyclical" or "structural" nature. Only time will tell how long the pandemic will last, its long-run effects on CA balances and if it will halt the trends in corporate saving and in the expansion of multinational activities, which dominated the past decade. What is certain now is that this major global shock will have strong implications, which will have to be carefully tackled in any future set-up of a CA model.

\section{A Annex}

This annex includes additional information on the countries included in our dataset and on the papers surveyed in our meta-analysis. 
Table A.1: List of countries considered

\begin{tabular}{ll}
\hline Advanced economies & Emerging economies \\
\hline Australia (AU) & Algeria (DZ) \\
Austria (AT) & Argentina (AR) \\
Belgium (BE) & Brazil (BR) \\
Canada (CA) & Bulgaria (BG) \\
Cyprus (CY) & Chile (CL) \\
Czech Republic (CZ) & China (CN) \\
Denmark (DK) & Croatia (HR) \\
Estonia (EE) & Hungary (HU) \\
Finland (FI) & India (IN) \\
France (FR) & Indonesia (ID) \\
Germany (DE) & Malaysia (MY) \\
Greece (GR) & Mexico (MX) \\
Hong Kong (HK) & Morocco (MA) \\
Iceland (IS) & Philippines (PH) \\
Ireland (IE) & Poland (PL) \\
Israel (IL) & Romania (RO) \\
Italy (IT) & Russian Federation (RU) \\
Japan (JP) & South Africa (ZA) \\
Korea, Republic of (KR) & Thailand (TH) \\
Latvia (LV) & Turkey (TR) \\
Lithuania (LT) & Venezuela (VE) \\
Luxembourg (LU) & \\
Malta (MT) & \\
Netherlands (NL) & \\
New Zealand (NZ) & \\
Norway (NO) & \\
Portugal (PT) & \\
Singapore (SG) & \\
Slovakia (SK) & \\
Slovenia (SI) & \\
Spain (ES) & \\
Sweden (SE) & \\
Switzerland (CH) & \\
Taiwan (TW) & \\
United Kingdom (GB) & \\
United States (US) & \\
\hline & \\
\hline
\end{tabular}

Notes: The classification follows that adopted in the IMF World Economic Outlook. 
Table A.2: List of surveyed CA model papers

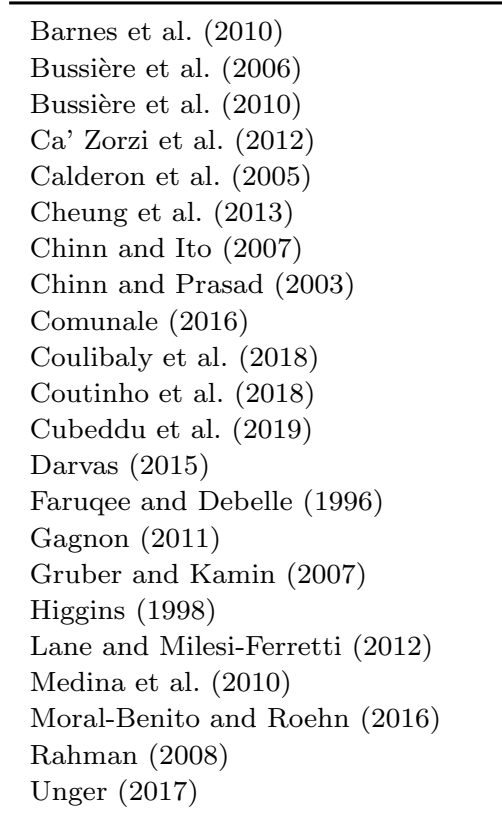

Notes: The articles are ordered in alphabetical order. The full references are found in the bibliography of this paper.

\section{References}

Abbas, S. M., J. Bouhga-Hagbe, A. Fatás, P. Mauro, and R. C. Velloso (2011): "Fiscal policy and the current account," IMF Economic Review, 59, 603-629.

ABEL, G. J. (2013): "Estimating global migration flow tables using place of birth data," Demographic Research, 28, 505-546.

Abiad, A., E. Detragiache, and T. Tressel (2010): "A new database of financial reforms," IMF Staff Papers, 57, 281-302.

Accoto, N., S. Federico, and G. Oddo (2021): "Trade in services, intangible capital, and the profit-shifting hypothesis," Bank of Italy mimeo.

Adler, K. And C. GRisse (2017): "Thousands of BEERs: Take your pick," Review of International Economics, 25, 1078-1104.

Aizenman, J. And Y. JinJARAK (2014): "Real estate valuation, current account and credit growth patterns, before and after the 2008-9 crisis," Journal of International Money and Finance, 48, 249-270.

Alexander, S. S. (1952): "Effects of a Devaluation on a Trade Balance," IMF Staff Papers, $2,263-278$.

Alfaro, L., S. Kalemli-Ozcan, and V. Volosovych (2008): "Why doesn't capital flow from rich to poor countries? An empirical investigation," Review of Economics and Statistics, $90,347-368$. 
Allione, G., R. Bronzini, and C. Giordano (2020): "Il recente andamento delle esportazioni del settore farmaceutico in Italia e nel Lazio," Bank of Italy Occasional Papers, 566.

Avdjiev, S., M. Everett, And P. R. Lane (2018): "Tracking the international footprints of global firms," .

Barnes, S., J. Lawson, And A. Radziwill (2010): "Current account imbalances in the euro area: A comparative perspective," OECD Economics Department Working Papers, 826.

Bassanetti, A., M. Caivano, And A. Locarno (2010): "Modelling Italian potential output and the output gap," Bank of Italy Working Papers, No. 771.

Behringer, J. And T. van Treeck (2018): "Income distribution and the current account," Journal of International Economics, 114, 238-254.

BÉnAssy-Quéré, A., A. LAhrèche RÉvil, And V. Mignon (2008): "Is Asia responsible for exchange rate misalignments within the G20?" Pacific Economic Review, 13, 46-61.

Bernanke, B. S. (2005): "The Global Saving Glut and the U.S. Current Account Deficit," Remarks at the Sandridge Lecture, Virginia Association of Economists, Richmond, Virginia.

Bernanke, B. S. and M. Gertler (1995): "Inside the Black Box: The Credit Channel of Monetary Policy Transmission," Journal of Economic Perspectives, 9, 27-48.

Bussière, M., M. CA' Zorzi, A. Chudík, And A. Dieppe (2010): "Methodological advances in the Assessment of Equilibrium Exchange Rates," ECB Working Papers, 1151.

Bussière, M., G. Callegari, F. Ghironi, G. Sestieri, and N. Yamano (2013): "Estimating trade elasticities: Demand composition and the trade collapse of 2008-2009," American Economic Journal: Macroeconomics, 5, 118-151.

Bussière, M., L. Ferrara, and J. Milovich (2015): "Explaining the Recent Slump in Investment: the Role of Expected Demand and Uncertainty," Banque de France Working Papers, 571, 31.

Bussière, M., M. Fratzscher, And G. J. Müller (2006): "Current Account Dynamics in OECD Countries and in the New EU Member States: An Intertemporal Approach," Journal of Economic Integration, 21, 593-618.

CA' Zorzi, M., A. Chudik, And A. Dieppe (2012): "Thousands of models, one story: Current account imbalances in the global economy," Journal of International Money and Finance, 31, $1319-1338$.

Calderon, C. A., A. Chong, And N. V. Loayza (2005): "Determinants of Current Account Deficits in Developing Countries," Contributions in Macroeconomics, 2.

Chamon, M. D. And E. S. Prasad (2008): "Why are saving rates of urban households in China rising?" American Economic Journal: Macroeconomics, 2, 93-130. 
Chen, P., L. Karabarbounis, And B. Neiman (2017): "The global rise of corporate saving," Journal of Monetary Economics, 89, 1-19.

Cheung, C., D. Furceri, and E. Rusticelli (2013): "Structural and cyclical factors behind current account balances," Review of International Economics, 21, 923-944.

Chinn, M. D. And H. Ito (2007): "Current account balances, financial development and institutions: Assaying the world saving glut," Journal of International Money and Finance, $26,546-569$.

Chinn, M. D. And E. S. Prasad (2003): "Medium-term determinants of current accounts in industrial and developing countries: An empirical exploration," Journal of International Economics, 59, 47-76.

Chudik, A. And M. H. Pesaran (2015): "Common correlated effects estimation of heterogeneous dynamic panel data models with weakly exogenous regressors," Journal of Econometrics, 188, 393-420.

Coeurdacier, N., Z. Barany, and S. Guibaud (2018): "Capital Flows in an Aging World," CEPR Discussion Paper Series, 13180.

Comunale, M. (2016): "A closer look at EU current accounts," CEIS Tor Vergata Research Papers, 393.

Coulibaly, D., B. Gnimassoun, and V. Mignon (2018): "Working Paper International Migration and Global Imbalances," CEPII Working Papers, 2.

Coutinho, L., A. Turrini, and S. Zeugner (2018): "Methodologies for the Assessment of Current Account Benchmarks," European Economy Discussion Paper, 086.

Cubeddu, L., S. Krogstrup, G. Adler, P. Rabanal, M. C. Dao, S. Ahmed Hannan, L. Juvenal, C. Osorio Buitron, C. Rebillard, D. Garcia-Macia, C. Jones, J. RoDriguez, K. S. Chang, D. Gautam, Z. Wang, And N. Li (2019): "The External Balance Assessment Methodology: 2018 Update," IMF Working Papers, 19, 1.

Dao, M. C. And C. Jones (2018): "Demographics, Old-Age Transfers and the Current Account," IMF Working Papers, 18, 1.

DARVAS, Z. (2015): "The grand divergence: Global and European current account surpluses," Bruegel Working Papers, 8.

Davis, D. R. And D. E. Weinstein (2002): "The Mystery of the Excess Trade (Balances)," American Economic Review, 92, 170-174.

Desbordes, R., G. Koop, And V. Vicard (2018): "One size does not fit all... panel data: Bayesian model averaging and data poolability," Economic Modelling, 75, 364-376.

Di Nino, V., M. Fidora, And M. Schmitz (2020): "Multinational enterprises, financial centres and their implications for external imbalances: a euro area perspective," ECB Economic Bulletin, 2. 
Docquier, F., G. Peri, And I. Ruyssen (2014): "The cross-country determinants of potential and actual migration," International Migration Review, 48, S37-S99.

Eugster, J. L., F. Jaumotte, M. Macdonald, and R. Piazza (2020): "Are Bilateral Trade Balances Irrelevant ?" IMF Working Papers, 210.

European Commission (2012): "Scoreboard for the surveillance of macroeconomic imbalances," .

Fabiani, S., S. Federico, And A. Felettigh (2016): "Adjusting the External Adjustment: Cyclical Factors and the Italian Current Account," Bank of Italy Occasional Papers, July 2016.

Fair, R. And K. Dominguez (1991): "'Effects of the Changing U.S. Age Distribution on Macroeconomic Equations," American Economic Review, 81, 1276-1294.

Faruqee, H. And G. Debelle (1996): "What Determines the Current Account? A CrossSectional and Panel Approach," IMF Working Papers, 58.

Feenstra, R., W. Hai, W. Woo, and S. Yao (1998): "The US-China Bilateral Trade Balance: Its Size and Determinants," NBER Working Papers, 6598.

Felbermayr, G. And Y. V. Yotov (2019): "From theory to policy with gravitas: A solution to the mystery of the excess trade balances," Kiel Working Papers, 2138.

Fidora, M., C. Giordano, And M. Schmitz (2021): "Real Exchange Rate Misalignments in the Euro Area," Open Economies Review, 32, 71-107.

Fleming, J. M. (1962): "Domestic Financial Policies under Fixed and under Floating Exchange Rates," Staff Papers - International Monetary Fund, 9, 369-380.

Gagnon, J. E. (2011): "Working Paper 11-1: Current Account Imbalances Coming Back," Peterson Institute for International Economics, 11-1.

(2017): "Do Governments Drive Global Trade Imbalances ?" Peterson Institute for International Economics Working Papers.

Gaiotti, E. (2013): "Credit availability and investment: Lessons from the "great recession"," European Economic Review, 59, 212-227.

Giordano, C. (2020): "An update of the Bank of Italy methodology underlying the estimation of price-competitiveness misalignments," Bank of Italy Occasional Papers, 556.

(2021): "How frequent a BEER? Assessing the impact of data frequency on real exchange rate misalignment estimation," The Scottish Journal of Political Economy, forthcoming.

Giordano, C., M. Marinucci, And A. Silvestrini (2019): "The macro determinants of firms' and households' investment: Evidence from Italy," Economic Modelling, 78, 118-133.

(2021): "Forecasting corporate capital accumulation in Italy: the role of survey-based information," Bank of Italy Occasional Papers, 596. 
Giri, R., S. Quayyum, And R. Yin (2019): "Understanding Export Diversification: Key Drivers and Policy Implications," IMF Working Papers, 19, 1.

Goldstein, M. And M. Khan (1985): "Income and price effects in foreign trade," in Handbook of International Economics, ed. by R. W. Jones and P. B. Kenen, Elsevier, vol. 2, chap. 20, 1041-1105, 1 ed.

Gourinchas, P.-O. AND H. Rey (2014): "External adjustment, global imbalances, valuation effects," in Handbook of International Economics, Elsevier B.V., vol. 4, 585-645.

Gourinchas, P.-O., R. Valdés, and O. Landerretche (2001): "Lending Booms: Latina America and the World," NBER Working Papers, 8249.

Gruber, J. W. AND S. B. KAmin (2007): "Explaining the global pattern of current account imbalances," Journal of International Money and Finance, 26, 500-522.

Guiso, L. AND G. PARIGi (1999): "Investment and demand uncertainty," Quarterly Journal of Economics, 114, 185-227.

Harberger, A. C. (1950): "Currency Depreciation, Income, and the Balance of Trade," Journal of Political Economy, 58, 47-60.

HEAD, K. AND J. RIES (2001): "Increasing returns versus national product differentiation as an explanation for the pattern of U.S.-Canada trade," American Economic Review, 91, 858-876.

Higgins, M. (1998): "Demography, National Savings, and International Capital Flows," International Economic Review, 39, 343-369.

IsARD, P. AND H. FARUQEe (1998): "Exchange rate assessment: extensions of the macroeconomic balance approach," IMF Occasional Papers, 167.

James, G., D. Witten, T. Hastie, and R. Tibshirani (2017): An Introduction to Statistical Learning: with Applications in R, Springer.

Ju, J. AND S. J. WeI (2010): "Domestic institutions and the bypass effect of financial globalization," American Economic Journal: Economic Policy, 2, 173-204.

Kapetanios, G., M. H. Pesaran, and T. Yamagata (2011): "Panels with non-stationary multifactor error structures," Journal of Econometrics, 160, 326-348.

Lane, P. R. and G. M. Milesi-Ferretti (2012): "External adjustment and the global crisis," Journal of International Economics, 88, 252-265.

(2018): "The External Wealth of Nations Revisited: International Financial Integration in the Aftermath of the Global Financial Crisis," IMF Economic Review, 66, 189-222.

Laursen, S. And L. A. Metzler (1950): "Flexible Exchange Rates and the Theory of Employment," The Review of Economics and Statistics, 32, 281.

Lucas, R. E. J. (1990): "Why Doesn' t Capital Flow from Rich to Poor Countries ?" The American Economic Review, 80, 92-96. 
Magnus, J. R., O. Powell, And P. Prüfer (2010): "A comparison of two model averaging techniques with an application to growth empirics," Journal of Econometrics, 154, 139-153.

Medina, L., J. Prat, And A. H. Thomas (2010): "Current Account Balance Estimates for Emerging Market Economies," IMF Working Papers, 43.

Mendoza, E. And M. Terrones (2012): "An anatomy of credit booms and their demise," NBER Working Papers, 18379.

Moral-Benito, E. (2012): "Determinants of economic growth: A bayesian panel data approach," Review of Economics and Statistics, 94, 566-579.

Moral-Benito, E. and O. Roenn (2016): "The impact of financial regulation on current account balances," European Economic Review, 81, 148-166.

Moulton, B. And P. VAN DE Ven (2018): "Addressing the challenges of globalisation in national accounts," OECD Working Party on Financial Statistics, No. 6.

Mundell, R. A. (1963): "Capital Mobility and Stabilization Policy under Fixed and Flexible Exchange Rates," The Canadian Journal of Economics and Political Science, 29, 475-485.

NG, S. (2013): "Variable Selection in Predictive Regressions," in Handbook of Economic Forecasting, Elsevier B.V., vol. 2, 752-789.

OBstfeld, M. (1995): "International Capital Mobility in the 1990s," in Understanding Interdependence: The Macroeconomics of the Open Economy, ed. by P. B. Kenen, Princeton University Press.

OBSTFELD, M. And K. Rogoff (1995): "The intertemporal approach to the current account," Handbook of International Economics, 3, 1731-1799.

(2009): "Global imbalances and the financial crisis: Products of common causes," CEPR Discussion Papers, 9605.

Phillips, S., L. Catão, L. Ricci, R. Bems, M. Das, J. Di Giovanni, D. Filiz Unsal, M. Castillo, J. Lee, J. Rodriguez, M. Vargas, J. Aizenman, M. D. Chinn, M. Evans, J. Gagnon, E. Lora, M. Obstfeld, P. Pedroni, D. Quinn, J. ShamBAUgh, AND A. TAYlor (2013): "The External Balance Assessment (EBA) Methodology The External Balance Assessment (EBA) Methodology," .

Rahman, J. (2008): "Current Account Developments in New Member States of the European Union: Equilibrium, Excess, and EU-Phoria," IMF Working Papers, 92.

Sachs, J. D. (1981): "The Current Account and macroeconomic Adjustment in the 1970s," Brookings Papers on Economic Activity, 12, 201-282.

Svensson, L. E. And A. Razin (1983): "The Terms of Trade and the Current Account : The Harberger-Laursen-Metzler Effect," Journal of Political Economy, 91, 97-125.

TeDeschi, R. (2018): "The Irish GDP in 2016. After the disaster comes a dilemma," Banca D'Italia. 
Tibshirani, R. (1996): "Regression Shrinkage and Selection Via the Lasso," Journal of the Royal Statistical Society: Series B (Methodological), 58, 267-288.

UngeR, R. (2017): "Asymmetric credit growth and current account imbalances in the euro area," Journal of International Money and Finance, 73, 435-451. 